\title{
Hydraulic Tomography for Estimating the Diffusivity of Heterogeneous Aquifers Based on Groundwater Response to Tidal Fluctuation in an Artificial Island in Taiwan
}

\author{
Jet-Chau Wen $\mathbb{D}^{1},{ }^{1,2}$ Hong-Ru Lin $\mathbb{D}^{3},{ }^{3}$ Tian-Chyi Jim Yeh, ${ }^{4}$ Yu-Li Wang, ${ }^{4}$ \\ Keng-Li Lin, ${ }^{5}$ and Shao-Yang Huang $\mathbb{D}^{2}$ \\ ${ }^{1}$ Department of Safety, Health and Environmental Engineering, National Yunlin University of Science and Technology, \\ Douliou, Yunlin, Taiwan \\ ${ }^{2}$ Research Center for Soil and Water Resources and Natural Disaster Prevention, National Yunlin University of Science and Technology, \\ Douliou, Yunlin, Taiwan \\ ${ }^{3}$ Doctoral Program, Graduate School of Engineering Science and Technology, National Yunlin University of Science and Technology, \\ Douliou, Yunlin, Taiwan \\ ${ }^{4}$ Department of Hydrology and Atmospheric Sciences, University of Arizona, Tucson, AZ, USA \\ ${ }^{5}$ Department of Environment, AECOM Taiwan Corporation, Kaohsiung, Taiwan
}

Correspondence should be addressed to Shao-Yang Huang; syh1019@ntu.edu.tw

Received 30 June 2017; Revised 15 December 2017; Accepted 6 February 2018; Published 15 April 2018

Academic Editor: Daniele Pedretti

Copyright (C) 2018 Jet-Chau Wen et al. This is an open access article distributed under the Creative Commons Attribution License, which permits unrestricted use, distribution, and reproduction in any medium, provided the original work is properly cited.

This study investigated the hydraulic properties of the heterogeneous aquifers of an artificial island (Yunlin Offshore Industrial Park) in Taiwan. The research was based on the groundwater level response affected by tidal fluctuation using the hydraulic tomography $(\mathrm{HT})$ to analyze the hydraulic diffusivity $(\alpha)$. Specifically, the power spectrum ratio of groundwater and tidal fluctuations derived from the Gelhar solution was used to estimate $\alpha$ in homogeneous aquifers; this, however, could not be applied in the artificial island. Next, the spatial distribution of the groundwater level response affected by tidal fluctuation was analyzed and found to be irregular, proving the existence of hydrogeological heterogeneity in the artificial island. Furthermore, the results of the estimated $\alpha$ using the HT showed low error and high correlation, $0.41 \mathrm{~m}^{2} / \mathrm{hr}$ and 0.83 , respectively, between the optimal estimated heterogeneous and reference $\alpha$ fields in the synthetic aquifer. Last, the HT was used in the real tested scenario. By comparing the predicted groundwater levels of the optimal estimated heterogeneous $\alpha$ field and the observed groundwater levels of the real aquifer, it was found that the correlation was higher than 0.99 . Therefore, the HT can be used to obtain the optimal estimated heterogeneous $\alpha$ field in the artificial island.

\section{Introduction}

The efficient planning of groundwater resources is necessary, and aquifer hydrogeological parameters provide valuable information when addressing groundwater resource management issues. The transmissivity $(T)$, hydraulic conductivity $(K)$, storage coefficient $(S)$, and hydraulic diffusivity $(\alpha)$ are essential parameters for controlling the groundwater flow in aquifers [1]. Additionally, a correct hydraulic parameterization of the aquifers has a direct impact for an accurate description of conservative and reactive transport in the subsurface $[2,3]$.
For estimating the hydraulic parameters from heterogeneous aquifers, Meier et al. [4] assumed that $T$ is heterogeneous and $S$ is homogeneous in a synthetic aquifer. They collected the late time drawdown data results of observation wells in pumping tests and used Jacob's method to estimate the $T$ and $S$ results. They found a strong spatial variability of the estimated $S$ result. Nevertheless, it often becomes problematic when determining the hydrogeological parameters of heterogeneous aquifers using analytical solutions of traditional homogeneous hypotheses [5].

For that reason and in order to obtain the heterogeneous hydrogeological parameters of an aquifer, Huang et al. [6] 
obtained the drawdown data of an aquifer in a real site using pumping tests. Those data were then used in numerical methods to estimate the heterogeneous hydrogeological parameters. Due to the geological heterogeneity, the fluid flow has the effect of preferential flow [7]. Russian et al. [8] presented a relatively simple multicontinuum approach that could be used to link the scaling of the discharge of the frequency transfer function (FTF) to a stochastic description of the catchment heterogeneity in the fractured aquifers. Pedretti et al. [9] focused on the scale dependence of hydraulic parameters in heterogeneous fractured aquifers based on the concept of transfer functions (TF). Their results showed that the scale dependence of $T$ was independent from the adopted formulation (single or dual-continuum), while $S$ was more sensitive to the presence of multiple continua. What is more, other relative researches used the hydraulic tomography (HT) to prove the heterogeneity of aquifers in real fields [6, 10-12].

However, the aforementioned literature focuses on inland studies to estimate aquifers with a heterogeneous hydrogeological distribution field. Hodgkinson et al. [13] analyzed the geological heterogeneity of a back-barrier sand island using the geophysical method. Other research investigations characterized the influence of lithological heterogeneity in groundwater systems on island atolls [14-16]. Such studies were based on the conditions of naturally occurring island aquifers with heterogeneous hydrogeology. Regarding the characteristics of aquifers in artificial islands, several studies investigated the groundwater behavior using analytical solutions $[17,18]$. Furthermore, Li et al. [19] estimated the hydrogeological parameters using semi-numerical simulations in homogeneous aquifers.

As the groundwater level responses to tidal fluctuation, the tidal methods have been widely used as a cost-effective way to assess major hydrogeological parameters in coastal aquifers [20-23]. Based on this feature, Gelhar [24] derived a formula for hydrogeological parameters and frequency (reciprocal of time) in unconfined aquifers. According to this, the natural tidal fluctuation in homogeneous aquifers can be used in the spectral analysis for determining $\alpha$ in coastal aquifers [25].

While the previously mentioned studies focused on the homogeneous hydrogeological parameters under uniform aquifers, the purpose of this study was to prove the existence of hydrogeological heterogeneity in artificial islands, as well as to develop a method for estimating the heterogeneous $\alpha$ field using the HT, when the groundwater level response is affected by the tidal fluctuation. The aquifer of an artificial island (Yunlin Offshore Industrial Park) in Taiwan was used as our case study.

\section{Materials and Methods}

2.1. Site Description. For this research, we selected the artificial island that is located at the mid-west coast of Taiwan (Figure 1(a)). It is approximately $8 \mathrm{~km}$ long, $3 \mathrm{~km}$ wide, and it expands in a territory of $22.55 \mathrm{~km}^{2}$. Its creation occurred due to the artificial land reclamation $(7 \mathrm{~m}$ under the surface level). Its major material is silty sand [27]. For this study, 55
TABLE 1: Slug test results of the 10 observation wells.

\begin{tabular}{lc}
\hline Well number & $K(\mathrm{~m} /$ day $)$ \\
\hline ob46 & 0.664 \\
ob47 & 0.283 \\
ob48 & 0.814 \\
ob49 & 0.234 \\
ob50 & 1.218 \\
ob51 & 1.745 \\
ob52 & 0.518 \\
ob53 & 1.123 \\
ob54 & 0.211 \\
ob55 & 1.849 \\
Mean & 0.866 \\
\hline
\end{tabular}

Source. Hsia et al. [26].

observation wells were used (Figure 1(a) circles). The average depth of all the 55 observation wells is $10 \mathrm{~m}$. Most screen intervals are opened at the depth ranging from 1 to $10 \mathrm{~m}$. Therefore, the aquifer is the phreatic aquifer.

The long-term data (11/07/2013 05/27/2014) of the rainfall, tidal, and groundwater levels are showed in Figure 1(b). It can be observed that January 2014 has no precipitation, whereas May 2014 presents the highest precipitation occurrence. Furthermore, the average tidal level was $0.4 \mathrm{~m}$ and the maximum tidal range was $4.23 \mathrm{~m}$ for the same period. The tide occurred every day and it was divided into two periods (semidiurnal tide), as it is shown in the shortterm data (01/01/2014 01/03/2014) of Figure 1(b). It should be noted that this study ignored the influence of seawater intrusion. The detailed long-term groundwater levels of the 55 observation wells can be found in the Supplementary Materials (available here). This study used 55 piezometers that were equipped with pressure transducers for automatic water level measurements at 1-hr intervals (Formosa Petrochemical Corporation provided 45 items of original groundwater level data-observation wells numbers ob01 to ob45. The groundwater level data from the remaining 10 observation wells were collected using the Solinst Model 3001 Levelogger). We selected 5 observation wells (ob37, ob44, ob33, ob05, and ob17 located east, south, west, north, and middle, resp.) out of the total 55, to illustrate the long-term groundwater level of the artificial island, as it is shown in Figure 1(b). The highest rise of the groundwater level was observed during the rainfall period (May 2014). In order to avoid the precipitation influence, this research focused on the nonrainfall period (00:00 a.m., 01/01/2014 11:00 a.m., 01/21/2014).

The slug test can be used to obtain the hydrogeological parameters of an aquifer. For the artificial island, the slug test results of 10 observation wells were obtained from a previous study [26], as it is shown in Table 1. It was found that the $K$ range was within $0.211 \sim 1.849 \mathrm{~m} /$ day, and the average $K$ was $0.866 \mathrm{~m} /$ day. However, the specific storage $\left(S_{s}\right)$ was not investigated in this study [26]. According to Freeze and Cherry [28], $S_{s}$ can be calculated by $S_{s}=\gamma\left(\alpha_{m}+n \beta\right)$, where $\gamma$ represents weight density, $\alpha_{m}$ represents compressibility of a porous medium, $\beta$ represents compressibility of water, and $n$ 

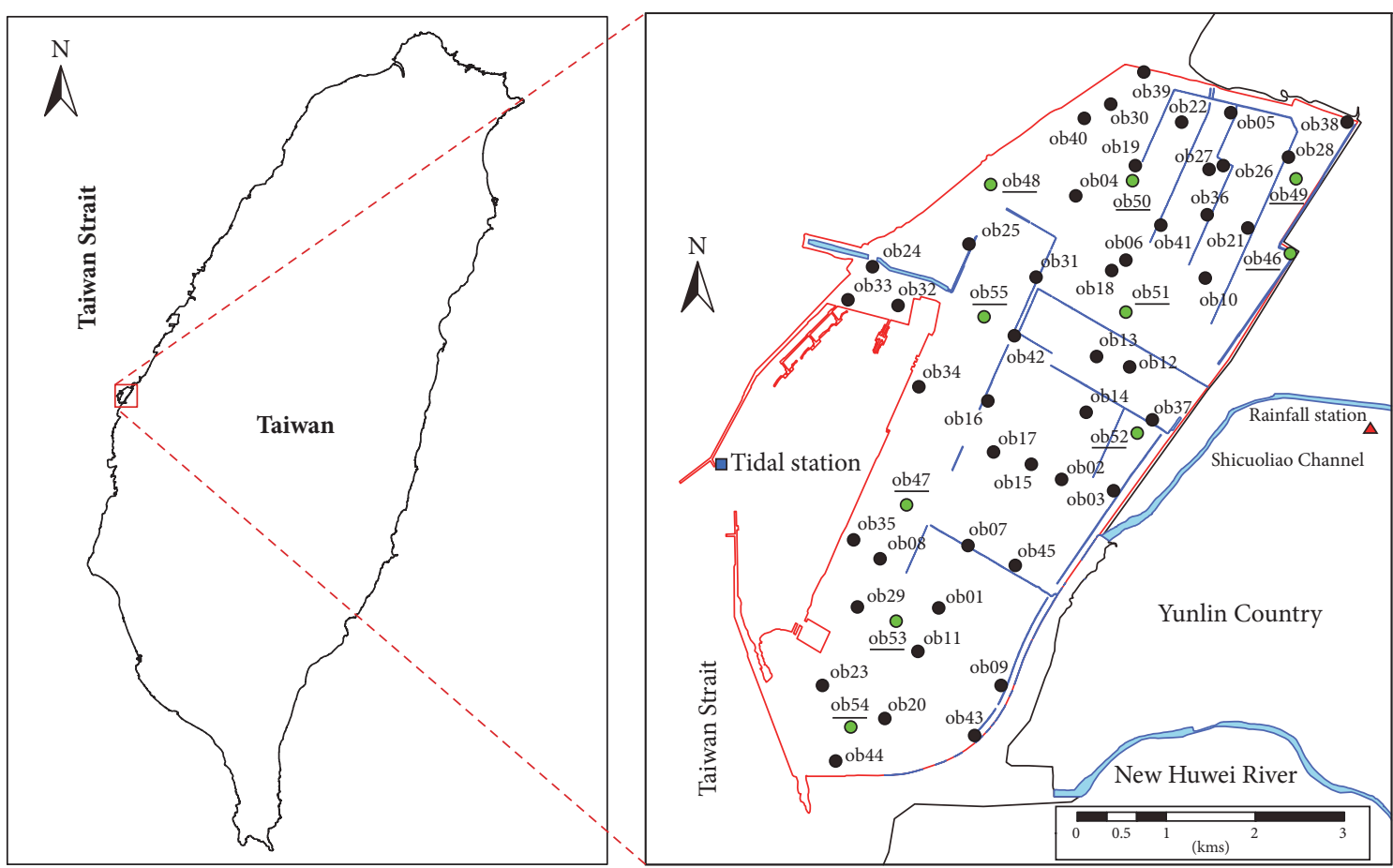

\section{Study area}

Channel

- Slug test well \& observation well

(a)
- Observation well

- Tidal station

- Rainfall station

(a)
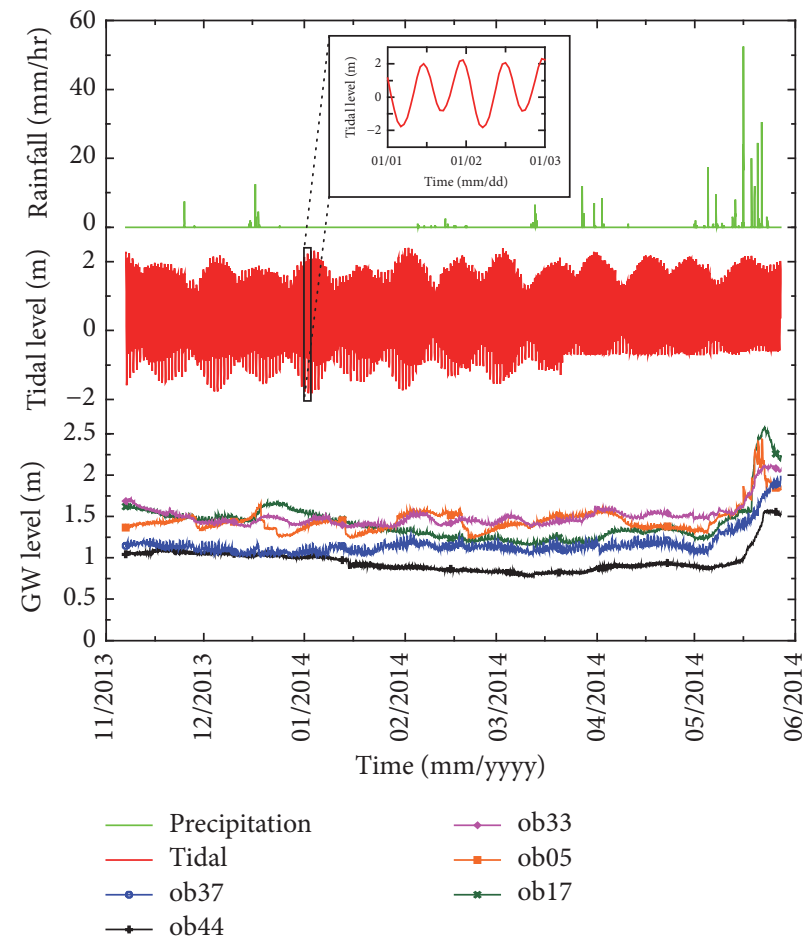

(b)

FIGURE 1: (a) Locations of the 55 observation wells (black and green circles), 10 of which belong to the slug test wells (green circles), a tidal station (blue square), and a rainfall station (red triangle); (b) long-term rainfall, tidal, and groundwater levels during the period 11/07/2013 05/27/2014, and short-term tidal levels during the period 01/01/2014 01/03/2014. 


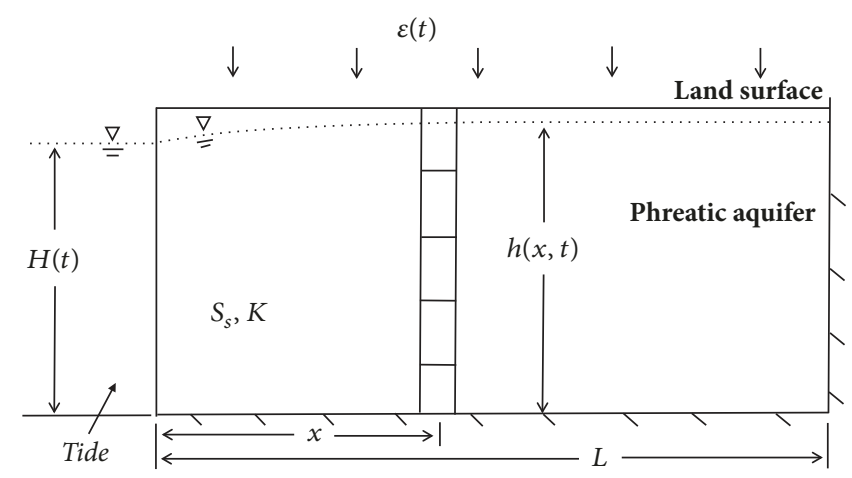

(a)

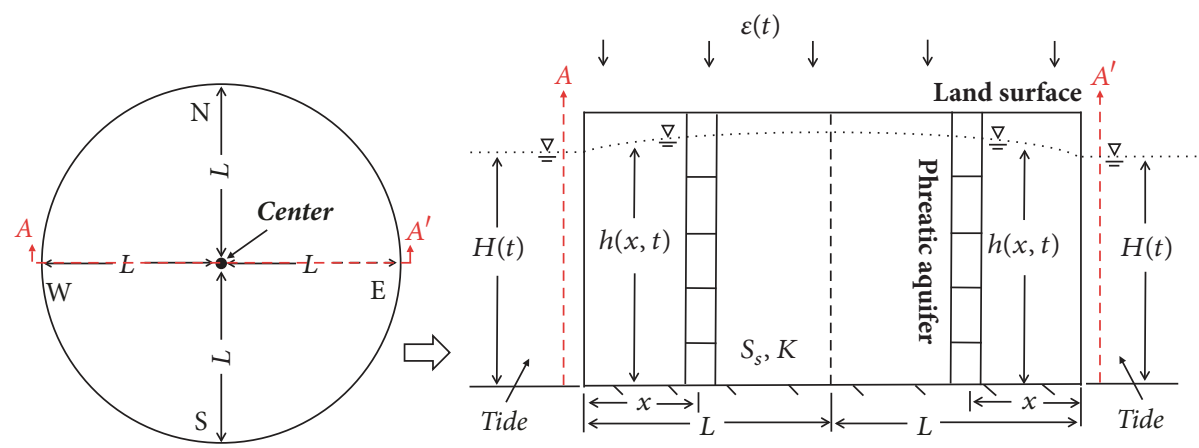

(b)

FIGURE 2: Phreatic aquifer scenarios of the (a) 1D Dupuit aquifer and (b) 2D axisymmetric Dupuit aquifer.

represents porosity. Therefore, $\gamma$ of water is $9.8 E+3\left(\mathrm{~N} / \mathrm{m}^{3}\right)$; the average $\alpha_{m}$ of sand and $\beta$ of water are $1.0 E-8\left(\mathrm{~m}^{2} / \mathrm{N}\right)$ and $4.4 E-10\left(\mathrm{~m}^{2} / \mathrm{N}\right)$, respectively [28, p. 55]. For the artificial island, Chien and Lin [27] found that $n$ is 0.41. Based on those analyses, $S_{s}$ is $9.98 E-5 \mathrm{~m}^{-1}$ and the spatially averaged hydraulic diffusivity $(\alpha)$ is $3.61 E+2 \mathrm{~m}^{2} / \mathrm{hr}$.

2.2. Hydrogeological Analysis of Homogeneous Aquifers. Previous researches $[24,25]$ estimated $\alpha$ using analytical solutions which assumed 1D homogeneous aquifers. According to Gelhar [24], the spectrum analysis is a technique for estimating the hydrogeological parameters by means of spatially distributed model based on the Dupuit theorem. This relates groundwater level response to stream fluctuation through a spectral representation of time series. Our study adopted and extended the approach by Gelhar [24] with estimating $\alpha$ in the artificial island using two different scenarios. One was the same solution for the $1 \mathrm{D}$ homogeneous aquifer (1D aquifer), as presented by Gelhar [24], and shown in Figure 2(a). The other one was the $2 \mathrm{D}$ axisymmetric homogeneous aquifer (2D aquifer), which is shown in Figure 2(b). The Gelhar solution [24] uses the power spectrum ratio of groundwater fluctuation and tidal fluctuation with the distance ratio of the observation well and aquifer to estimate $\alpha$. However, does this always apply in aquifers of artificial islands?

We considered the linearized form of the classical Dupuit approximation [29]. It is given by Gelhar [24] as

$$
S_{s} \frac{\partial h}{\partial t}=K \frac{\partial^{2} h}{\partial x^{2}}+\varepsilon
$$

where $h(x, t)[\mathrm{L}]$ is the hydraulic head, $x[\mathrm{~L}]$ is the distance of the observation well from the tidal boundary, $S_{s}\left[\mathrm{~L}^{-1}\right]$ is specific storage, $K[\mathrm{~L} / \mathrm{T}]$ is the hydraulic conductivity, and $\varepsilon$ $[\mathrm{L} / \mathrm{T}]$ represents accretion. An aquifer of finite length $L[\mathrm{~L}]$ is connected to the tidal boundary (Figures 2(a) and 2(b)). This study ignored the accretion $(\varepsilon=0)$, and the solution of the Fourier transform of (1) that is given by Gelhar [24] as

$$
\begin{aligned}
& \frac{S_{h h}(\omega, x)}{S_{H H}(\omega)}=\frac{e^{2 A}+e^{-2 A}+2 \cos 2 A}{e^{2 C}+e^{-2 C}+2 \cos 2 C}, \\
& \quad A=\sqrt{\frac{\Omega}{2}}\left(\frac{x}{L}-1\right), C=\sqrt{\frac{\Omega}{2}}, \Omega=\frac{\omega L^{2}}{\alpha}, \alpha=\frac{K}{S_{s}},
\end{aligned}
$$

where $S_{H H}$ and $S_{h h}$ are the spectral density functions of the tidal fluctuation and groundwater fluctuation, respectively, $\alpha\left[\mathrm{L}^{2} / \mathrm{T}\right]$ is the hydraulic diffusivity, $\Omega$ is the dimensionless frequency, and $\omega[\mathrm{rad} / \mathrm{T}]$ is the angular frequency.

The ratio of the power spectrum refers to the groundwater fluctuation response of an observation well that is affected by tidal fluctuation; $\alpha$ can be estimated from (2). However, (2) determines the length of the aquifer $(L)$, while Gelhar [24] determines $L$ from the impermeable boundary. The aquifer impermeable boundaries of an island are difficult to define. In the real aquifer, we estimated a constant equivalent length $\left(L_{\text {equiv }}\right)$ representing the length of the aquifer.

This study used the software VSAFT2 [30] to simulate the aforementioned scenarios in $1 \mathrm{D}$ and $2 \mathrm{D}$ aquifers. The first scenario of this research was the same as the $1 \mathrm{D}$ aquifer presented by Gelhar [24]. The grid size length and width were 
$10 \mathrm{~m}$ each. $\alpha$ was $3.61 E+2 \mathrm{~m}^{2} / \mathrm{hr}$ as previously mentioned. We assumed 7 different $L(100 \mathrm{~m}, 250 \mathrm{~m}, 500 \mathrm{~m}, 750 \mathrm{~m}, 1,000 \mathrm{~m}$, $2,500 \mathrm{~m}$, and $5,000 \mathrm{~m}$ ) to estimate $L_{\text {equiv }}$. For each $L$, the observation wells were placed in every $10 \mathrm{~m}$. Then, we created a sin wave as the boundary condition (to represent the tidal fluctuation) with a 12-hr period and a tidal range of $2 \mathrm{~m}$. The boundary behavior was a periodically varying head boundary condition on one end and an impermeable boundary on the other (Figure 2(a)). The total simulation time was $256 \mathrm{hr}$ and the time step was $1 \mathrm{hr}$.

The simulation was executed based on the 7 different $L$ of the 1D aquifer. From each $L$, we obtained 256 simulation groundwater level datasets in every observation well. Next, we used the Fast Fourier Transform (FFT) to analyze the spectrums of the groundwater level of each observation well and tidal fluctuation. Then, we applied (2) in the MATLAB built-in function (least squares fitting) to estimate $L_{\text {equiv }}$ for the 7 different $L$ based on the aforementioned spectrums and the known conditions ( $\alpha$ and $x / L$ ). When $\alpha$ is a fixed condition in the $1 \mathrm{D}$ aquifer, a set of $L_{\text {equiv }}$ for different aquifer lengths is expected to be obtained.

The second scenario was based on the 2D aquifer (Figure 2(b)). The setting conditions were the same as in the $1 \mathrm{D}$ aquifer (e.g., grid size, boundary condition, locations of observation wells, and $L$ ). However, because the $2 \mathrm{D}$ aquifer is an axisymmetric aquifer, the assumed $L$ was the distance from the boundary to the center of a circle. Furthermore, the $\mathrm{N}$ direction was selected to estimate $L_{\text {equiv }}$ from the 7 different $L$. We used the estimated $L_{\text {equiv }}$ method to the $2 \mathrm{D}$ aquifer in order to investigate the feasibility of the Gelhar solution [24] in the $2 \mathrm{D}$ aquifer.

\subsection{Hydrogeological Analysis of Heterogeneous Aquifers}

2.3.1. Spatial Distribution of Groundwater Level Affected by Tidal Fluctuation. This analysis investigated the spatial distribution based on the data obtained from groundwater levels of the 55 observation wells and tidal fluctuation in the frequency and time domains. Specifically, 484 groundwater and tidal level datasets were obtained for each observation well, as well as the tidal station during the nonrainfall period (00:00 a.m., 01/01/2014 11:00 a.m., 01/21/2014). By following this analysis, it was possible to detect the existence of heterogeneous characteristics in the real aquifer. This study used two approaches to analyze the spatial distribution of groundwater levels of the 55 observation wells affected by tidal fluctuation in the frequency domain: (1) the continuous wavelet transform (CWT) and (2) the wavelet coherence (WC).

The wavelet transform can be used to decompose a time series over a time-scale space. It provides a visualization of power distribution along time and frequency. A detailed mathematical analysis of wavelet transform can be found in Walker [31]. The CWT is widely applied in hydrology sciences [32-36]. Therefore, we used the CWT analysis to obtain the power spectrums of the groundwater levels of the 55 observation wells and tidal fluctuation. According to Torrence and Compo [37], we selected the Morlet function of the "mother" wavelet of CWT because it is a Gaussian function and provides accurate localization in the frequency domain. The tidal level is a regular fluctuation; therefore, we obtained the maximum spectrum on a fixed frequency with different time using the CWT approach. The average spectrum of the tidal level was calculated by averaging the maximum spectrum at different times and fixed frequencies. Similarly, we calculated the average spectrum of the groundwater level of each observation well for the same tidal frequency at different times. Then, these 55 average spectrums were divided by the average spectrum of the tidal level in order to obtain the tidal efficiency (TE) results of the 55 observation wells, as well as the TE ranges that were between 0 and 1. Last, the spatial distribution of the TE results was obtained using the kriging method (linear variogram function) of the software Surfer.

The WC analysis investigates the correlation of two signals in the frequency domain. It also analyzes the correlation between river stage and groundwater levels [36]. We used the WC to analyze the correlation between the groundwater levels of the 55 observation wells and tidal fluctuation, as well as to calculate the average WC results at different times by fixed frequency (same frequency as with the CWT approach). Last, the spatial distribution of the WC results was obtained using the kriging method. Both CWT and WC analyses were based on the cwt and wcoherence of the MATLAB built-in function.

In the time domain, the correlation and time lag between the groundwater levels of the 55 observation wells and tidal fluctuation were investigated using the cross-correlation analysis. Prior to that, this study removed the seasonal trend of the groundwater and tidal levels. Thus, the tidal perturbation $\left(h_{t}\right)$ was obtained by the linear regression of the tidal level. The groundwater perturbation $\left(h_{g}\right)$ of each observation well was obtained by the polynomial regression of the groundwater level. $h_{t}$ and $h_{g}$ were evaluated using the following equation:

$$
\begin{aligned}
& \operatorname{Cor}(L) \\
& =\frac{(1 /(N-L)) \sum_{i=1}^{N-L}\left[\left(h_{t}(i)-\bar{h}_{t}\right)\left(h_{g}(i+L)-\bar{h}_{g}\right)\right]}{\sqrt{(1 / N) \sum_{i=1}^{N}\left(h_{t}(i)-\bar{h}_{t}\right)^{2}} \sqrt{(1 / N) \sum_{i=1}^{N}\left(h_{g}(i)-\bar{h}_{g}\right)^{2}}}
\end{aligned}
$$

where $\operatorname{Cor}(L)$ is the cross-correlation and $L[\mathrm{~T}]$ is time lag or sampling point lag; $h_{t}[\mathrm{~L}]$ and $h_{g}[\mathrm{~L}]$ represent the time series of the tidal and groundwater perturbations, respectively; $\bar{h}_{t}$ and $\bar{h}_{g}$ are the mean perturbations; and $N$ is the total number of data in time series.

Because the tides have periodic fluctuation, the crosscorrelation between the tidal and groundwater levels at lag times has a periodic rise and fall. For this study, the periodic rise of the first maximum cross-correlation for all the 55 observation wells was used to obtain the spatial distributions of the first maximum cross-correlation and its time lag using the kriging method. The time lag refers to the time elapse of the groundwater level affected by tidal fluctuation at a given location lag.

2.3.2. The HT in Synthetic Aquifers. This research investigated the estimated heterogeneous $\alpha$ field using the HT in the 


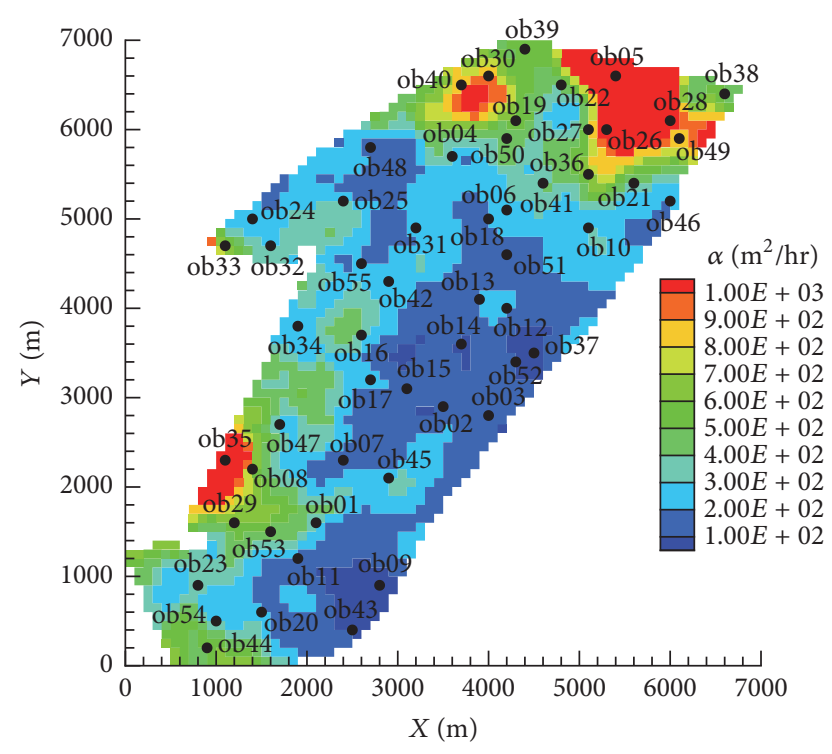

FIgURE 3: Reference $\alpha$ field. Locations of the 55 observation wells (black circles).

artificial island based on the groundwater level response affected by tidal fluctuation. Then, we evaluated the detailed spatial variations of the aquifer subsurface hydraulic properties using the HT, based on the successive linear estimator (SLE) [38-40]. The HT has been evolved from the CAT (computerized axial tomography) scan concept of medical sciences and geophysics. The concept of HT involves stressing an aquifer by tidal fluctuation and collecting the head response of each observation well. The head response results of each observation well can be used to inverse the hydraulic parameters. This is a successful technique, as it can be used for artificial stress, such as pumping test [6,10-12, 41], or for natural stress, such as river fluctuation $[36,42]$.

Specifically for this study, we first tested a synthetic heterogeneous $\alpha$ field that is known (reference $\alpha$ field). Then, we simulated its groundwater levels based on the 55 observation wells responses induced by the known tidal fluctuation. According to the groundwater levels of the 55 observation wells and tidal fluctuation, we verified the estimated heterogeneous $\alpha$ field result using the HT. Although the reference $\alpha$ field was a known value in the synthetic aquifer, we investigated the feasibility of the HT to analyze the estimated heterogeneous $\alpha$ field in the synthetic aquifer.

Based on the study area range, a 2D horizontal domain of $70 \times 70$ square elements was built. Each element was $100 \mathrm{~m} \times$ $100 \mathrm{~m}$; the total element numbers were 2,267. As previously mentioned, $\alpha$ was $3.61 E+2\left(\mathrm{~m}^{2} / \mathrm{hr}\right)$. The variance of $\ln \alpha$ (i.e., the natural logarithm of $\alpha$ ) was 0.5 . The correlation scales were $1,500 \mathrm{~m}$ for both $x$ and $y$ directions. They were selected to be approximately half of the width of the study area. Additionally, they provided a description of the average size of the heterogeneity. Figure 3 shows the reference $\alpha$ field that has been generated by a spectral method random field generator [43].

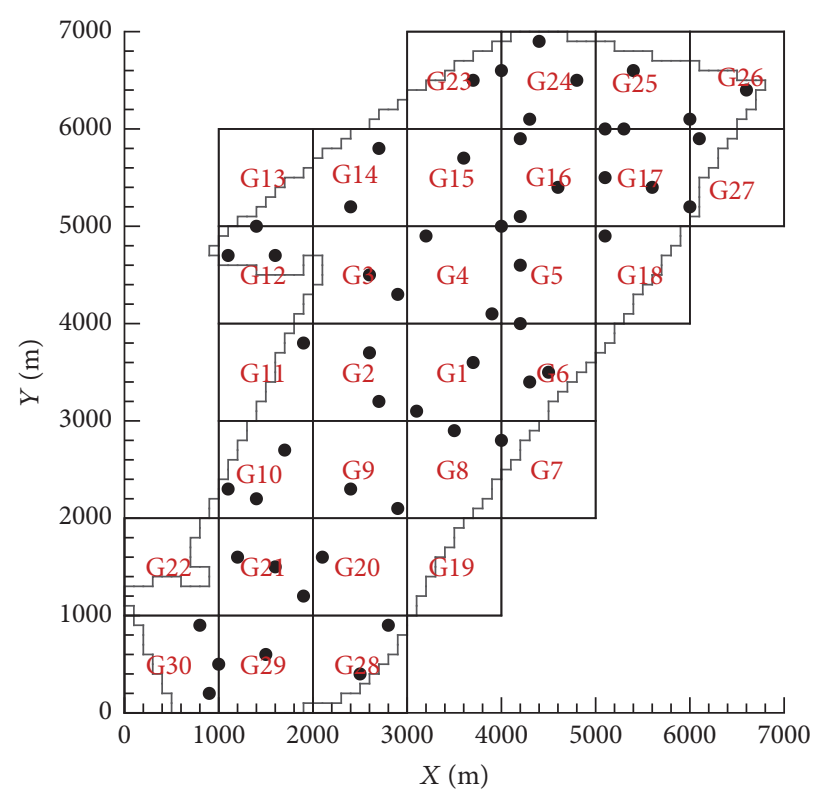

FIGURE 4: Grid numbers and locations of the observation wells used for the inverse model.

For this research, the boundary condition refers to a periodically varying head based on time series of the real tidal fluctuation. The initial condition was the distribution of the groundwater levels of the 55 observation wells using kriging method at 00:00 a.m., 01/01/2014. The simulation time lasted for $24 \mathrm{hr}$ and the time step was $1 \mathrm{hr}$. We used the HT in the VSAFT2 to simulate the forward model and obtain the observed groundwater level of each observation well (24 datasets). The total observed groundwater level datasets of all the 55 observation wells were 1,320.

In the inverse model, we estimated the total number of the observation wells (the current observation well and all the previous ones; e.g., the 3rd observation well refers to the $3 \mathrm{rd}, 2 \mathrm{nd}$, and 1st observation wells) that are required to obtain the optimal estimated heterogeneous $\alpha$ field. Specifically, we selected the observation wells using the grid method starting from the 1st observation well (observed groundwater levels of 24 datasets) and increasing it up to the 55th observation well (observed groundwater levels of 1,320 datasets). Then, we created a 2D horizontal domain with grids of $1,000 \mathrm{~m} \times$ $1,000 \mathrm{~m}$. The total number of grids was 30 , and they were defined as G1, G2, .., G30. We started from the centered observation well and used the clockwise direction for the remaining observation wells (Figure 4). The observation wells were sequentially selected from $G 1$ to G30 until they were 55 in total. If there were more than one observation wells in a grid, the one closer to the center of the grid was prioritized. If there were no observation wells in a grid, the grid was skipped. This process was repeated until all the observation wells were estimated. The sequential clockwise order is shown in Table 2. Based on our knowledge, this method for obtaining the optimal estimated heterogeneous $\alpha$ field is innovative for aquifer grid sampling in artificial islands; therefore, it is highlighted in this study. 
TABLE 2: Sequential clockwise order of the observation wells used for the inverse model.

Sequential clockwise order of the observation wells ob14, ob16, ob55, ob13, ob51, ob52, ob03, ob02, ob07, ob47, ob34, ob32, ob24, ob25, ob04, ob41, ob21, ob10, ob01, ob53, ob40, ob22, ob05, ob38, ob46, ob43, ob20, ob23, ob15, ob17, ob42, ob31, ob12, ob37, ob45, ob08, ob33, ob48, ob50, ob36, ob29, ob39, ob26, ob28, ob49, ob09, ob54, ob44, ob18, ob35, ob06, ob27, ob11, ob19, ob30

The HT was applied from the 1st observation well to the 55 th in order to investigate each estimated heterogeneous $\alpha$ field. Next, the mean absolute error (MAE), root mean square error (RMSE), and correlation coefficient (COR) between the estimated heterogeneous and reference $\alpha$ fields in different quantitative observation wells were calculated, so as to estimate the required number of observation wells for delivering the optimal estimated heterogeneous $\alpha$ field. The lower the MAE and RMSE and the higher the COR, the more consistent the estimates. We used the optimal estimated heterogeneous $\alpha$ field to simulate the forward model and obtain the predicted groundwater levels of the observation wells that were not used in the inverse model. Then, we calculated the error and correlation between the predicted and observed groundwater levels using the same observation wells, so as to validate the groundwater levels using the optimal estimated heterogeneous $\alpha$ field.

2.3.3. The HT in Real Aquifers. The HT was used in the real aquifer that has known conditions (e.g., boundary condition, initial condition, and simulation time). These conditions were the same as those with the synthetic aquifer. The observed groundwater levels were obtained from the historical records of the artificial island.

For the inverse model, that is, the use of the HT in the real aquifer, we followed the same procedures as those in the synthetic aquifer. We selected the observation wells according to the sequential clockwise order (Table 2). Then, we calculated the estimated heterogeneous $\alpha$ field error and correlation results by comparing 54 observation well pairs. Each pair included a current observation well and its following (e.g., 1st-2nd, 2nd-3rd, ..., 54th-55th). By doing so, we estimated the required number of observation wells for delivering the optimal estimated heterogeneous $\alpha$ field. Next, we used the optimal estimated heterogeneous $\alpha$ field to simulate the forward model and obtain the predicted groundwater levels of the observation wells that were not used in the inverse model. We calculated the error and correlation by comparing the predicted and observed groundwater levels at the same observation wells in order to validate the optimal estimated heterogeneous $\alpha$ field.

2.3.4. Evaluation Criteria. The MAE, RMSE, and COR $(0 \leq$ $\mathrm{COR} \leq 1)$ were the performance statistics for evaluating (a) the similarity between the estimated heterogeneous and reference $\alpha$ fields in the synthetic aquifer; (b) the similarity between the estimated heterogeneous $\alpha$ fields of the observation well pairs in the real aquifer; (c) the similarity between the predicted and observed groundwater levels in the synthetic aquifer; and (d) the similarity between the predicted and observed groundwater levels in the real aquifer.

\section{Results and Discussion}

3.1. Homogeneous Aquifers. Based on the estimated $L_{\text {equiv }}$ results of the $1 \mathrm{D}$ aquifer (Figures $5(\mathrm{a})$ and 5(b)), when $L$ was from $500 \sim 5,000 \mathrm{~m}$, the error results showed a steady state (error $=1.72 \% \sim 0.94 \%)$. This proves the effectiveness of the estimated $L_{\text {equiv }}$ at the $1 \mathrm{D}$ aquifer. Regarding the estimated $L_{\text {equiv }}$ results of the $2 \mathrm{D}$ aquifer (Figures 6(a) and 6(b)), due to the grid limitations of the VSAFT2, we could only analyze 4 aquifer lengths $(100 \mathrm{~m}, 250 \mathrm{~m}, 500 \mathrm{~m}$, and $750 \mathrm{~m})$ in which the error results did not show a steady state (the error dropped between the estimated $L_{\text {equiv }}$ and the theory $L$ ). By comparing the error results of $1 \mathrm{D}$ and $2 \mathrm{D}$ aquifers (Figures 5(b) and 6(b)), it can be observed that the latter presents higher error for all its aquifer lengths. For instance, at $500 \mathrm{~m}$, the 1D and 2D aquifer errors were $1.72 \%$ and $9.51 \%$, respectively. The reason for this condition is that the $2 \mathrm{D}$ aquifer has two degrees of freedom. Therefore, the Gelhar solution [24] cannot be applied to the $2 \mathrm{D}$ aquifer.

In line with our findings, the $2 \mathrm{D}$ scenario for a homogeneous island aquifer cannot be described by the Gelhar solution [24]. In other words, heterogeneous characteristics may exist in artificial island aquifers. This is why we adopted a heterogeneous concept to describe the hydrogeological characteristics of the real aquifer.

\subsection{Heterogeneous Aquifers}

3.2.1. Results of Spatial Distribution of Groundwater Level Affected by Tidal Fluctuation. In the frequency domain, the TE results between the groundwater levels of the 55 observation wells and tidal fluctuation are shown in Figure 7(a). The TE range was from $2.43 E-6$ to $5.88 E-2$. It can be observed that the TE results of the ob03 and ob43 presented the highest values: $5.88 E-2$ and $5.44 E-2$, respectively. Moreover, in the southeast coast of the real aquifer, the groundwater level was significantly affected by tidal fluctuation. The TE results showed irregular distribution, a fact that proves the existence of heterogeneous characteristics in the real aquifer. Additionally, the WC results (Figure $7(\mathrm{~b})$ ) showed a range from 0.63 to 0.99 . Specifically, the results of 8 observation wells (ob03, ob09, ob24, ob34, ob39, ob43, ob44, and ob52) presented values higher than 0.9 . This occurred because the aforementioned observation wells were relatively close to the boundary of the artificial island, so they were susceptible to tidal fluctuation.

In the time domain, the first maximum cross-correlation results (Figure $7(\mathrm{c})$ ) showed a range from 0.03 to 0.99 . The first maximum cross-correlation results of 4 observation wells (ob03, ob24, ob39, and ob43) presented values higher than 0.9. Again, these observation wells were relatively close to the boundary of the artificial island, so they were susceptible to tidal fluctuation. The time lag results (Figure $7(\mathrm{~d})$ ) showed that the time lag of the observation wells near the boundary was relatively short. 


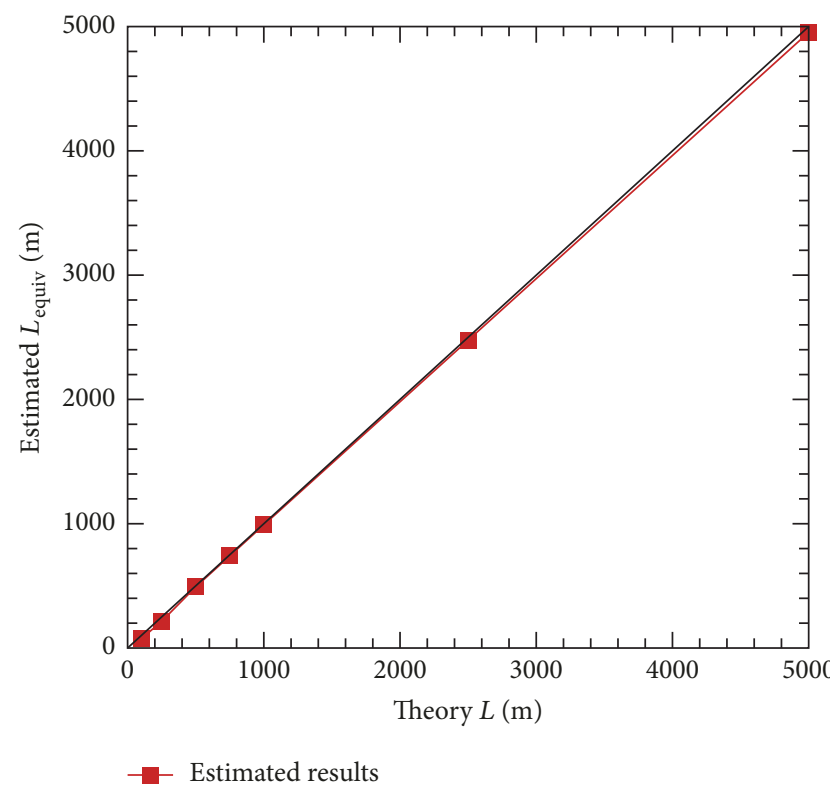

(a)

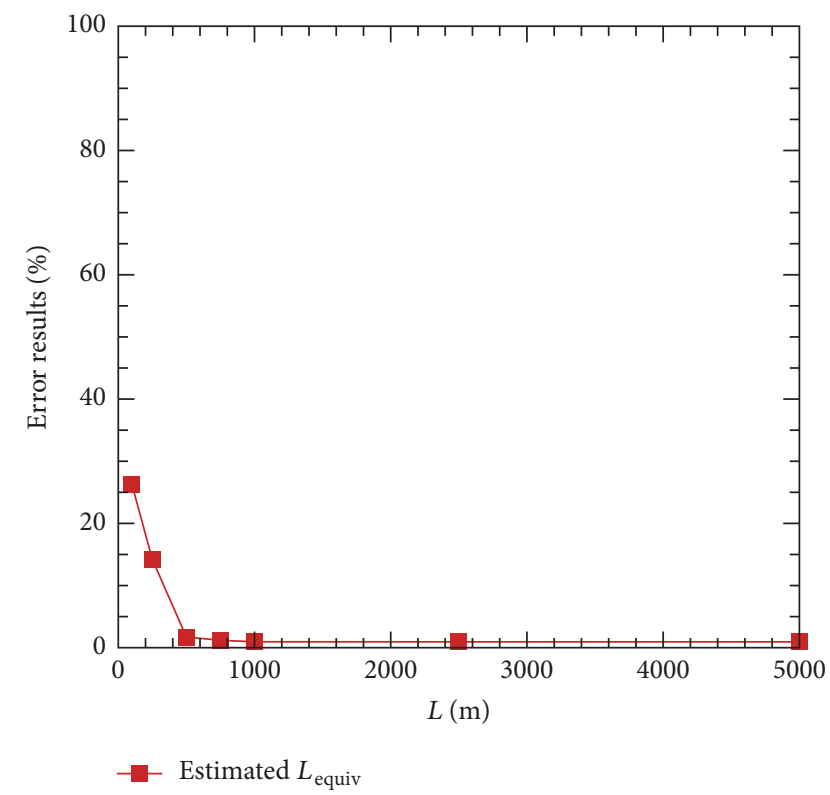

(b)

FIGURE 5: Results of 1D aquifer of the (a) scatter plot of the theory $L$ versus the estimated $L_{\text {equiv }}$ and (b) error graph of the estimated $L_{\text {equiv }}$.

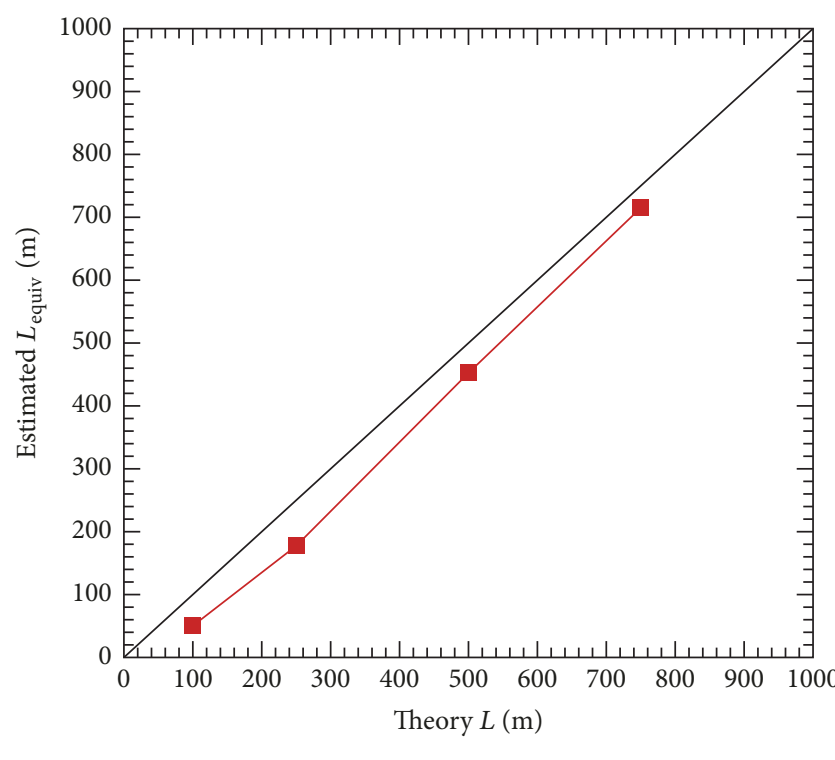

Estimated results

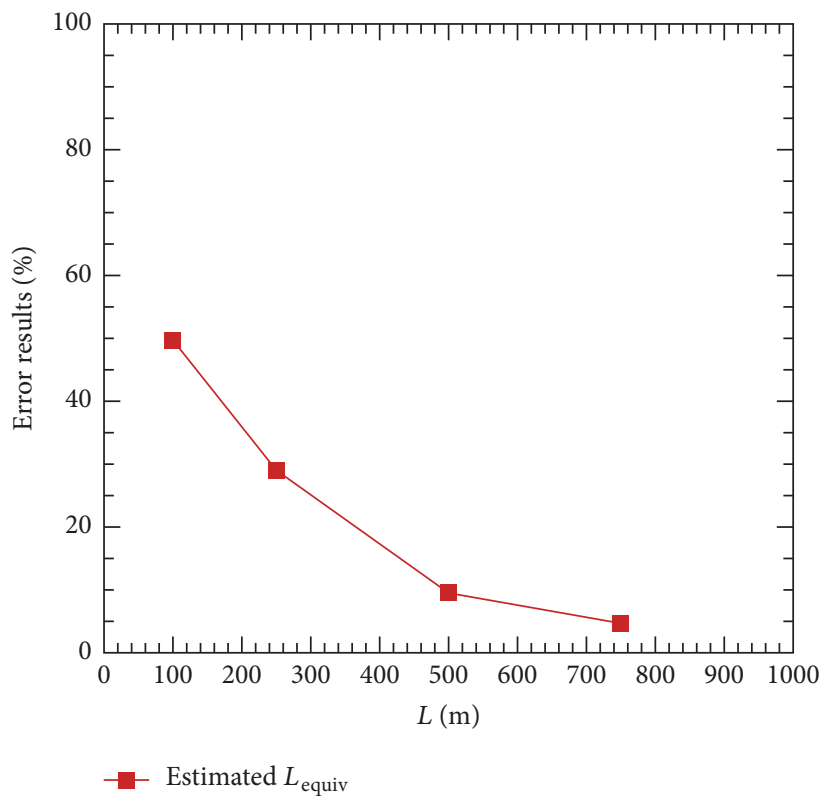

(b)

FIGURE 6: Results of the $2 \mathrm{D}$ aquifer of the (a) scatter plot of the theory $L$ versus the estimated $L_{\text {equiv }}$ and (b) error graph of the estimated $L_{\text {equiv }}$.

The results of spatial distributions of the TE, WC, first maximum cross-correlation, and time lag analyses presented many similarities, as it is shown in Figures 7(a), 7(b), 7(c), and $7(\mathrm{~d})$. The area around the boundary of the aquifer was affected by the tide, whereas the middle area of the artificial island was not. Regarding the observation wells, the ob03 and ob43 were affected the most and were followed by ob09, ob24, ob34, ob39, ob44, and ob52. Due to the tidal fluctuation in the areas of the aforementioned observation wells, the pressure wave propagation was relatively fast and therefore, the results of the TE, WC, first maximum cross-correlation, and time lag analyses showed irregular spatial distributions. This also proves the existence of heterogeneous characteristics in the real aquifer.

3.2.2. Results of the HT Used in Synthetic Aquifers. The groundwater levels of all the 55 observation wells were used to investigate the estimated heterogeneous $\alpha$ field using the 




(a)

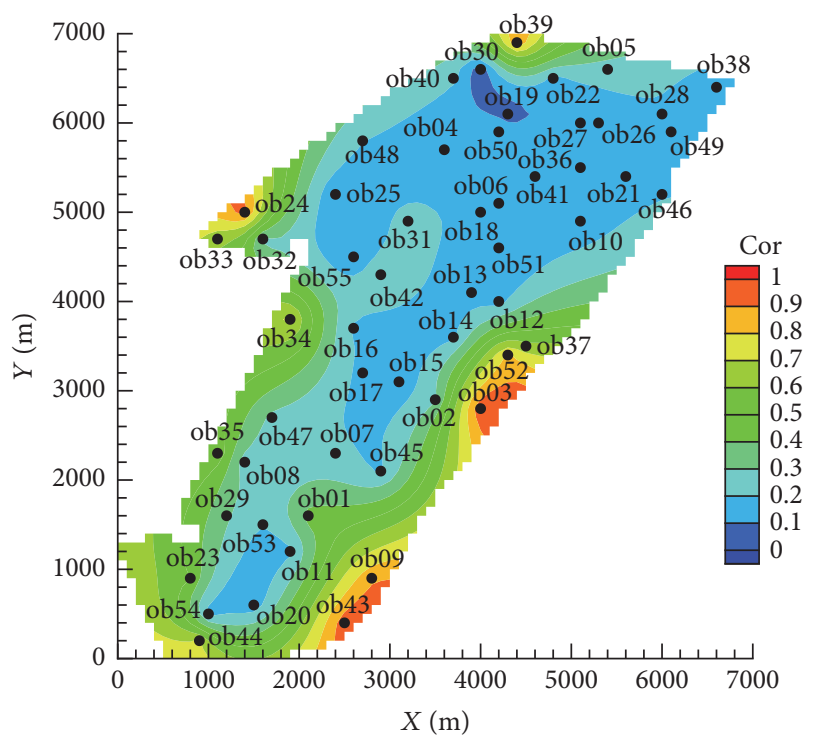

(c)

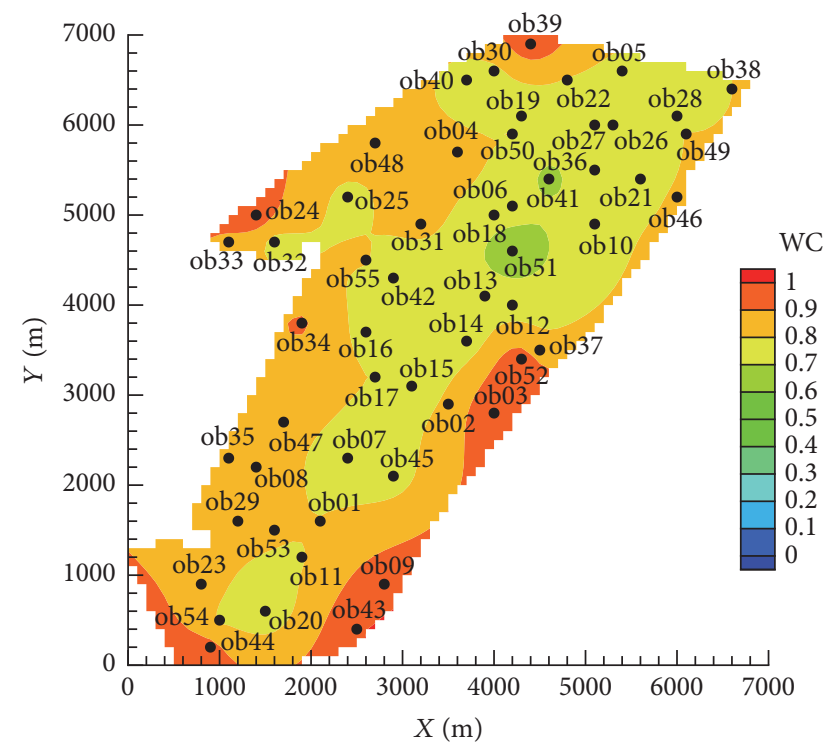

(b)

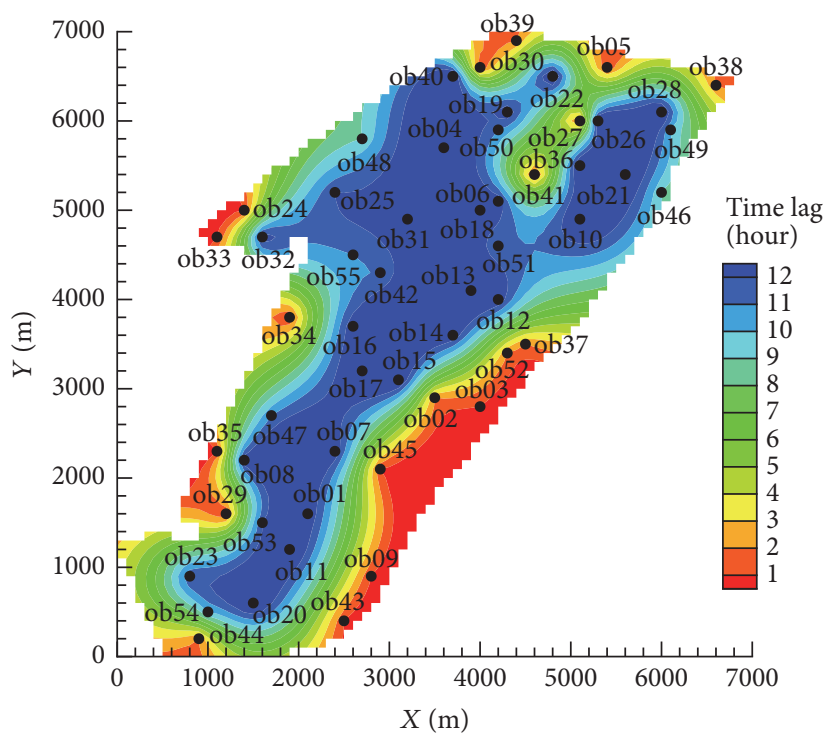

(d)

FIGURE 7: Spatial distributions of the groundwater level affected by tidal fluctuation. (a) Tidal efficiency (TE) results based on the continuous wavelet transform (CWT) approach between the groundwater and tidal levels; (b) wavelet coherence (WC) results based on the wavelet coherence approach between the groundwater and tidal levels; (c) first maximum cross-correlation results between the groundwater and tidal levels; and (d) time lag results between the groundwater and tidal levels.

HT in the synthetic aquifer. The error and correlation results between the estimated heterogeneous and reference $\alpha$ fields are shown in Figure 8(a). It can be observed that they presented a steady state from the 26 th to the 55 th observation well. Hence, the optimal estimated heterogeneous $\alpha$ field was obtained after reaching the 26th observation well (RMSE: $0.410 \mathrm{~m}^{2} / \mathrm{hr}$ and COR: 0.830 ). The arithmetic mean and variance of the total estimated heterogeneous $\alpha$ fields are shown in Figure 8(b). Furthermore, the results of the arithmetic mean and variance of the estimated heterogeneous $\alpha$ field in the 26th observation well were closer to the reference $\alpha$ field. It should be noted that from the 26th observation well to the 55th, the arithmetic mean and variance presented a steady state. Therefore, in this study, the estimated heterogeneous $\alpha$ field of the 26th observation well was used as the optimal estimated heterogeneous $\alpha$ field.

Figure 9(a) presents the optimal estimated heterogeneous $\alpha$ field. The high and low $\alpha$ patterns were generally similar to those of the reference $\alpha$ field (Figure 3). By comparing the $\alpha$ results between the optimal estimated heterogeneous and reference $\alpha$ fields at the same elements (2,267 datasets in total) in Figure 9(b), it can be observed that the $\alpha$ results are on or near the 45-degree line, showing a high correlation (COR: $0.830)$. 


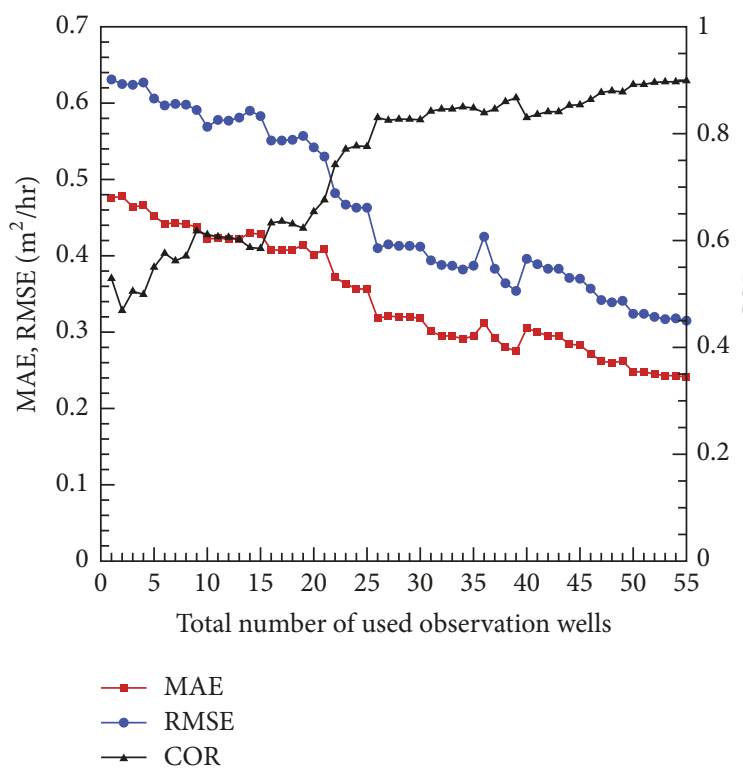

(a)

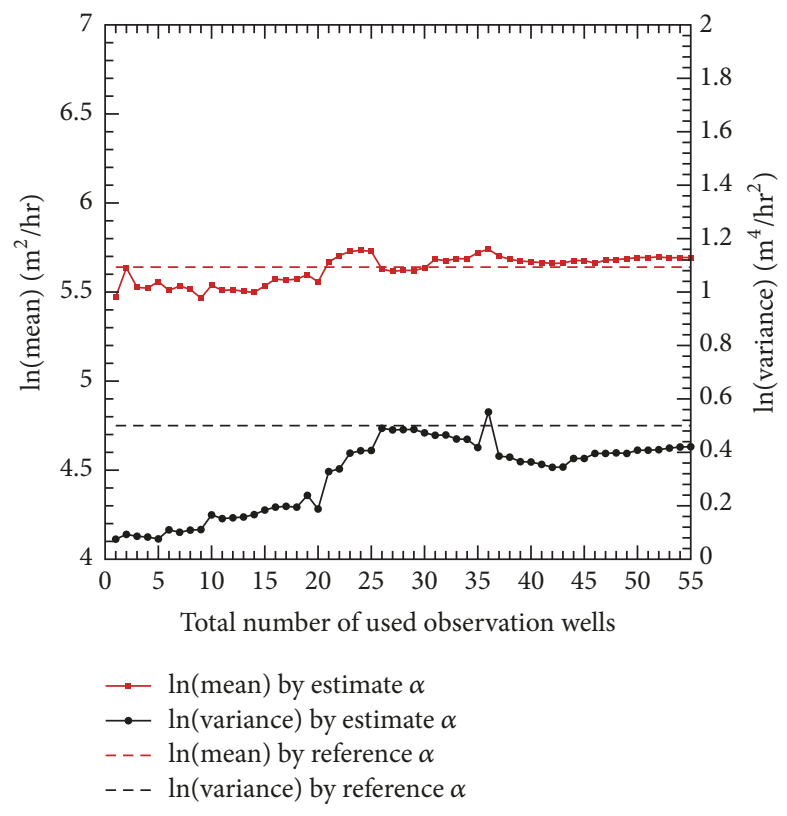

(b)

Figure 8: Total number of used observation wells for investigating the estimated heterogeneous $\alpha$ field results in the synthetic aquifer. (a) Error and correlation graph of the estimated $\alpha$ versus the reference $\alpha$; (b) the $\ln$ (mean) and $\ln$ (variance) graph of the estimated $\alpha$ and reference $\alpha$.

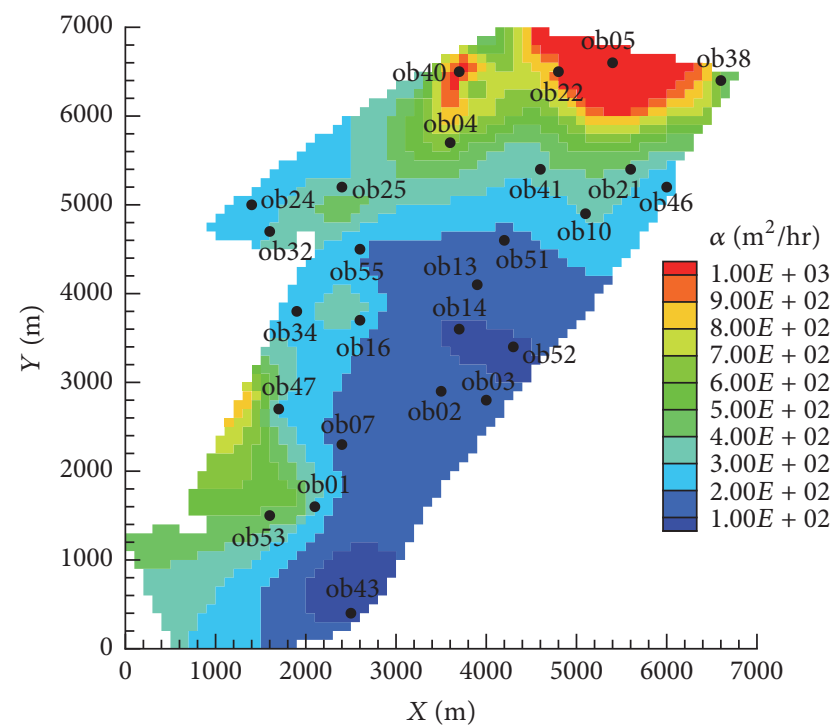

(a)

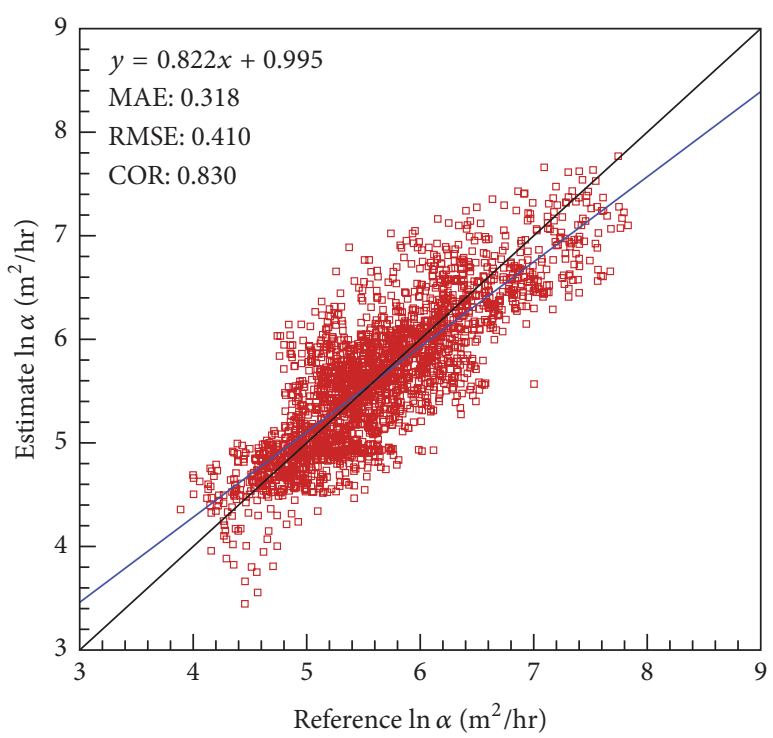

(b)

Figure 9: (a) Optimal estimated heterogeneous $\alpha$ field in the synthetic aquifer (26th observation well used for the inverse model); (b) scatter plot of $\ln \alpha$ between the optimal estimated heterogeneous and reference $\alpha$ fields.

Next, we compared the predicted groundwater levels of the optimal estimated heterogeneous $\alpha$ field and the observed groundwater levels of the reference $\alpha$ field. Both were obtained from the observation wells that were not used in the inverse model (the last 29 observation wells), as shown in Figure 10 (696 datasets in total). It can be observed that the groundwater level results are on or near the 45-degree line. Also, at the observation well ob35, the values of the predicted groundwater levels were higher than those of the observed groundwater level. This shows that the optimal estimated heterogeneous and reference $\alpha$ fields had few similarities in the region around the ob35. However, the error and correlation results of the groundwater levels of the last 29 observation wells were $0.086 \mathrm{~m}$ and 0.977 , respectively. Hence, the optimal estimated heterogeneous $\alpha$ field presented in general the same hydrogeological characteristics as the 


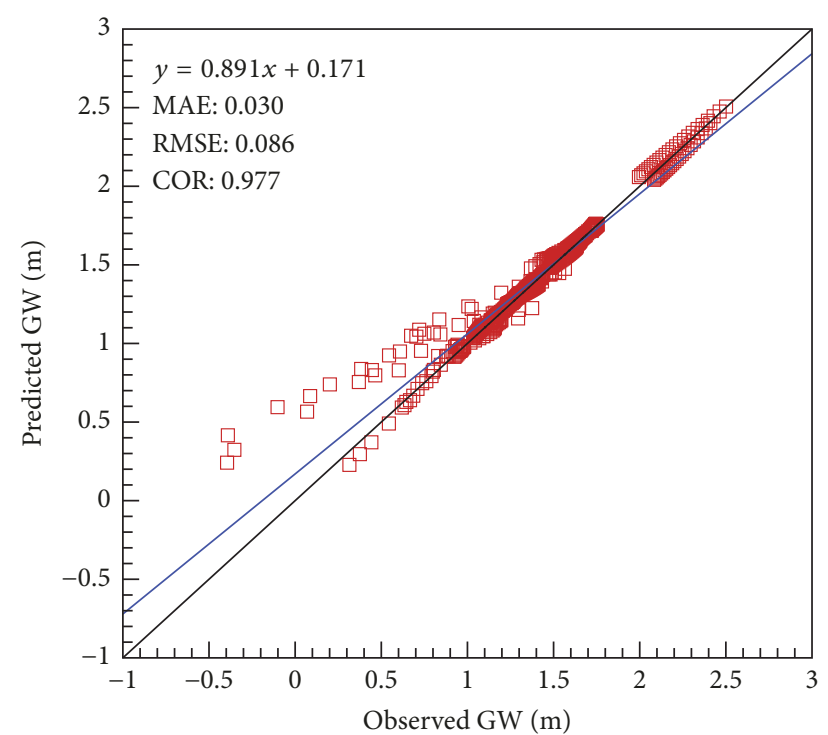

FIGURE 10: Scatter plot of the predicted groundwater levels of the optimal estimated heterogeneous $\alpha$ field and the observed groundwater levels of the reference $\alpha$ field in the synthetic aquifer.

reference $\alpha$ field. This proves that the HT was successfully used in our study for investigating the optimal estimated heterogeneous $\alpha$ field in the synthetic aquifer.

3.2.3. Results of the HT Used in Real Aquifers. Next, we used the HT to the real tested scenario and analyzed the estimated heterogeneous $\alpha$ field error and correlation for all the observation well pairs (Figure 11(a)). According to Figure 11(a), the optimal estimated heterogeneous $\alpha$ field could be obtained after reaching the 50th-51st observation well pair. The RMSE and COR of this pair were $0.02 \mathrm{~m}^{2} / \mathrm{hr}$ and 1.000 , respectively. The arithmetic mean and variance of the total estimated heterogeneous $\alpha$ fields are shown in Figure 11(b). The arithmetic mean and variance of the estimated heterogeneous $\alpha$ field from the 50th-51st observation well pair to the 54th-55th presented a steady state. Therefore, the estimated heterogeneous $\alpha$ field of the 50th observation well was used as the optimal estimated heterogeneous $\alpha$ field.

Figure 12(a) shows the results of the optimal estimated heterogeneous $\alpha$ field. It can be observed that the real aquifer has high $\alpha$ regions at middle and southeast, indicating that these high $\alpha$ regions are more sensitive to tidal fluctuation. Also, the high and low estimated $\alpha$ patterns of the regions that are close to the perimetric boundary of the artificial island in Figure 12(a) resemble the high and low first maximum crosscorrelation results in Figure 7(c). However, this phenomenon cannot be observed in the middle areas of the artificial island. Furthermore, the regions of the high estimated $\alpha$ results in Figure 12(a) have low uncertainty, which is the distribution of the residual variances of the estimated $\alpha$, shown in Figure 12(b). For that reason, the estimated results near the high $\alpha$ regions are more reliable.

Next, we compared the predicted groundwater levels of the optimal estimated heterogeneous $\alpha$ field and the observed groundwater levels of the historical records of the real aquifer. Both were obtained from the observation wells that were not used in the inverse model (the last 5 observation wells), as shown in Figure 13(a) (120 datasets in total). It can be observed that the groundwater level results are on or near the 45-degree line. The RMSE and COR results of the groundwater levels of the last 5 observation wells were $0.021 \mathrm{~m}$ and 0.997 , respectively. Hence, the optimal estimated heterogeneous $\alpha$ field presented in general the same hydrogeological characteristics as the real aquifer. Also, this study used the optimal estimated heterogeneous $\alpha$ field to simulate the forward model and obtain the predicted groundwater levels of all the 55 observation wells from 3 different time periods, each of which lasted for $72 \mathrm{hr}(01 / 08 / 2014 \sim$ 01/10/2014, 01/11/2014 01/13/2014, and 01/14/2014 01/16/2014; 3,960 datasets/period). Then, we compared the predicted groundwater levels of the optimal estimated heterogeneous $\alpha$ field and the observed groundwater levels of the historical records of the real aquifer, as shown in Figures 13(b), 13(c), and $13(\mathrm{~d})$. It can be observed that the correlation results were higher than 0.99. Again, this demonstrated that the optimal estimated heterogeneous $\alpha$ field presented in general the same hydrogeological characteristics as the real aquifer. Additionally, the HT sufficiently investigated the optimal estimated heterogeneous $\alpha$ field.

\section{Conclusions}

This study proved the effectiveness of the HT for estimating $\alpha$ of heterogeneous aquifers based on groundwater level responses that are affected by tidal fluctuation in the artificial island. According to our research results, the following should be highlighted:

(1) The spectrum analysis was used to estimate $L_{\text {equive }}$ of $1 \mathrm{D}$ and $2 \mathrm{D}$ aquifers at different $L$. We found that the error result of the estimated $L_{\text {equive }}$ of the $2 \mathrm{D}$ aquifer was higher than that of the $1 \mathrm{D}$ aquifer by $7 \%$ in the same distance $(L)$. This occurred due to the fact that the $2 \mathrm{D}$ aquifer has two degrees of freedom. Therefore, the $2 \mathrm{D}$ scenario for a homogeneous island aquifer cannot be described by the Gelhar solution [24].

(2) The CWT, WC, cross-correlation, and time lag analyses were used to investigate the spatial distributions of the groundwater level affected by tidal fluctuation. We found that the pressure wave propagation was relatively fast in the southeast coast of the real aquifer, due to the tidal fluctuation. Additionally, the spatial distribution results of TE, WC, first maximum crosscorrelation, and time lag analyses were irregular. This proves the existence of heterogeneous hydrogeological characteristics in the artificial island.

(3) We investigated the estimated heterogeneous $\alpha$ field in the synthetic aquifer using the HT. The results showed that the optimal estimated heterogeneous $\alpha$ field could be obtained by the 26th observation well; the RMSE and COR were $0.410 \mathrm{~m}^{2} / \mathrm{hr}$ and 0.830 , respectively. By comparing the optimal estimated 


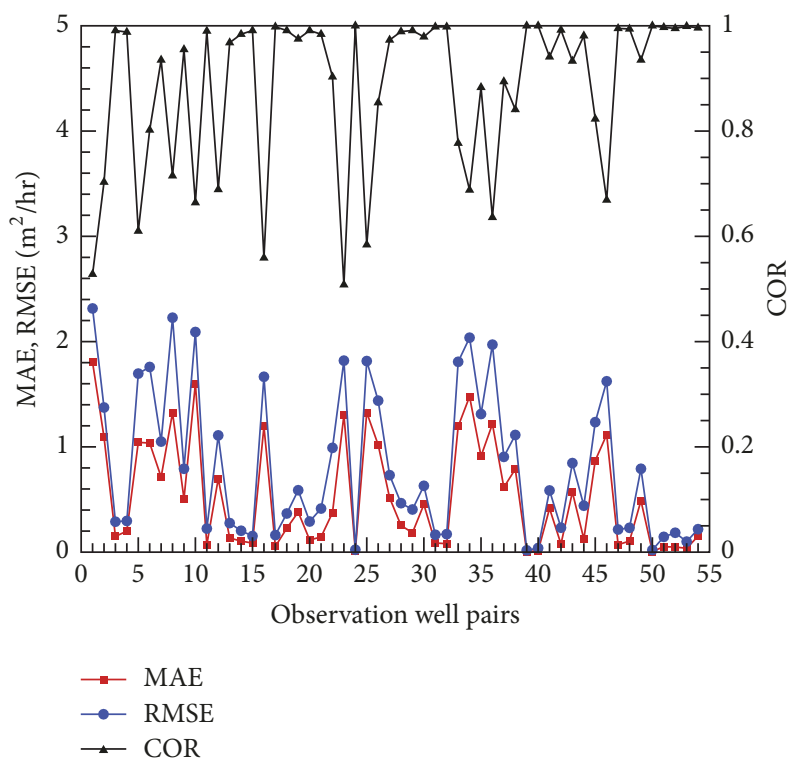

(a)

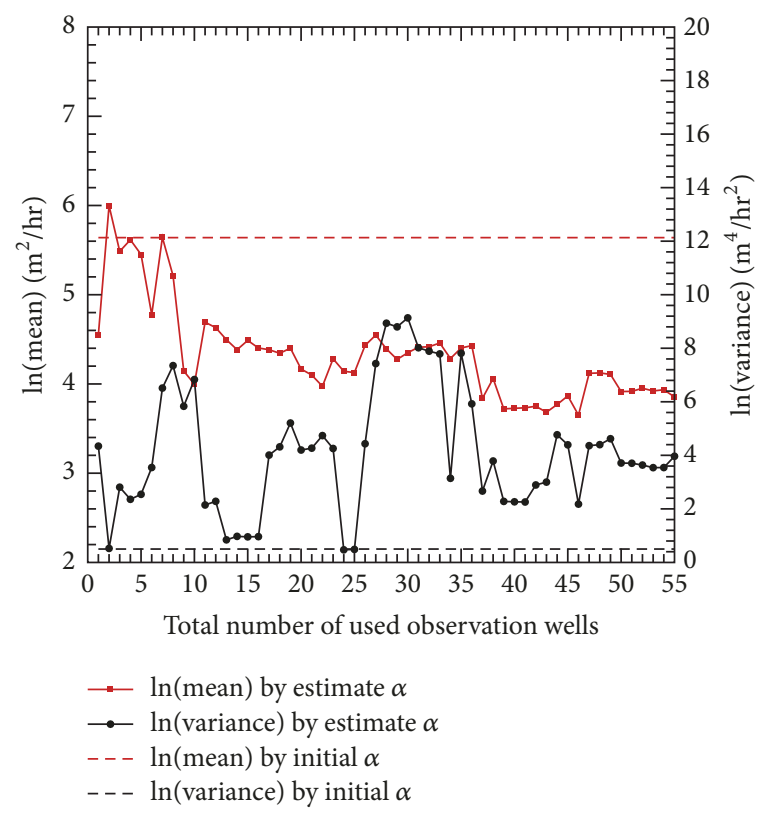

(b)

FIGURE 11: Total number of used observation wells for investigating the estimated heterogeneous $\alpha$ field results in the real aquifer. (a) Error and correlation graph of the estimated $\alpha$ obtained from the current observation well and its following (observation well pair); (b) the ln (mean) and $\ln$ (variance) graph of the estimated $\alpha$ and initial $\alpha$.

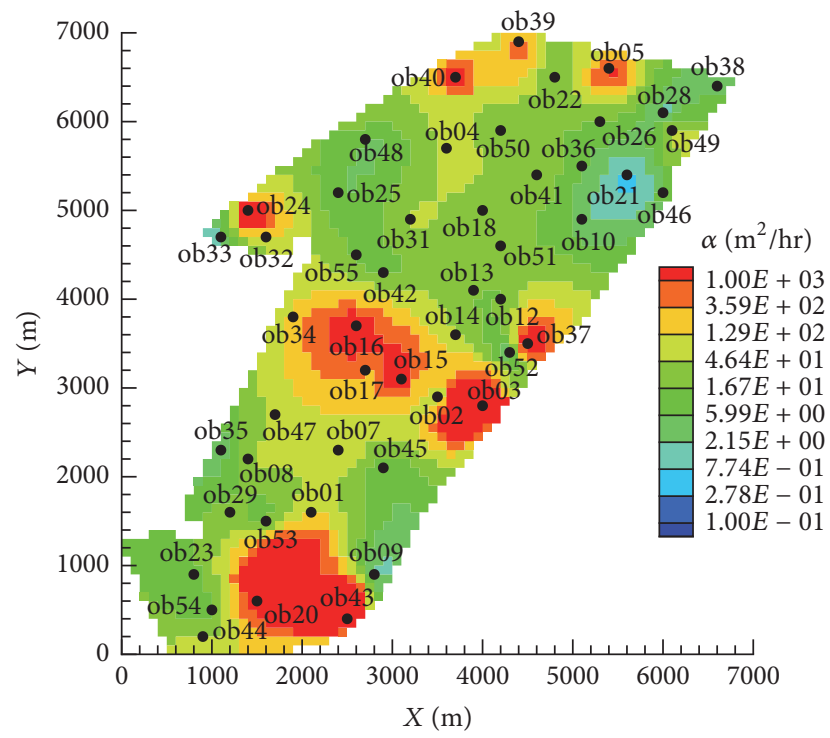

(a)

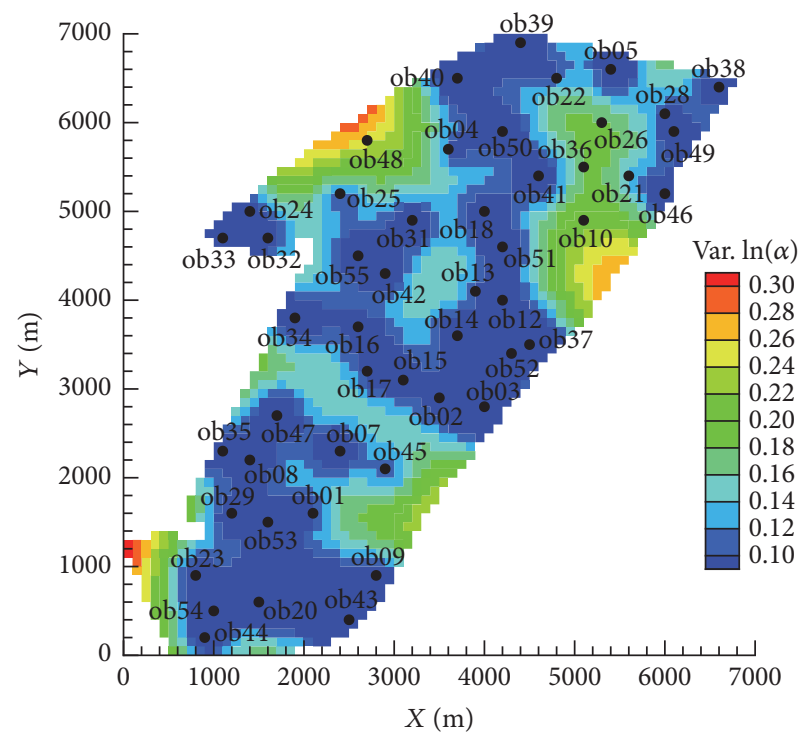

(b)

FIGURE 12: Optimal estimated heterogeneous $\alpha$ field in the real aquifer (50th observation well used for the inverse model). (a) Optimal estimated heterogeneous $\alpha$ field; (b) uncertainty of $\alpha$ estimation.

heterogeneous and reference $\alpha$ fields, we found similarities in both high and low $\alpha$ regions. According to the predicted groundwater level results of the 29 last observation wells, the RMSE and COR were $0.086 \mathrm{~m}$ and 0.977 , respectively. Hence, it has been demonstrated that the HT can sufficiently investigate the optimal estimated heterogeneous $\alpha$ field in synthetic aquifers.
(4) We investigated the estimated heterogeneous $\alpha$ field in the real tested scenario using the HT. The results showed that the optimal estimated heterogeneous $\alpha$ field could be obtained by the 50th observation well; the RMSE and COR were $0.020 \mathrm{~m}^{2} / \mathrm{hr}$ and 1.000 , respectively. The optimal estimated heterogeneous $\alpha$ field and the first maximum cross-correlation distribution showed that the high correlation regions 


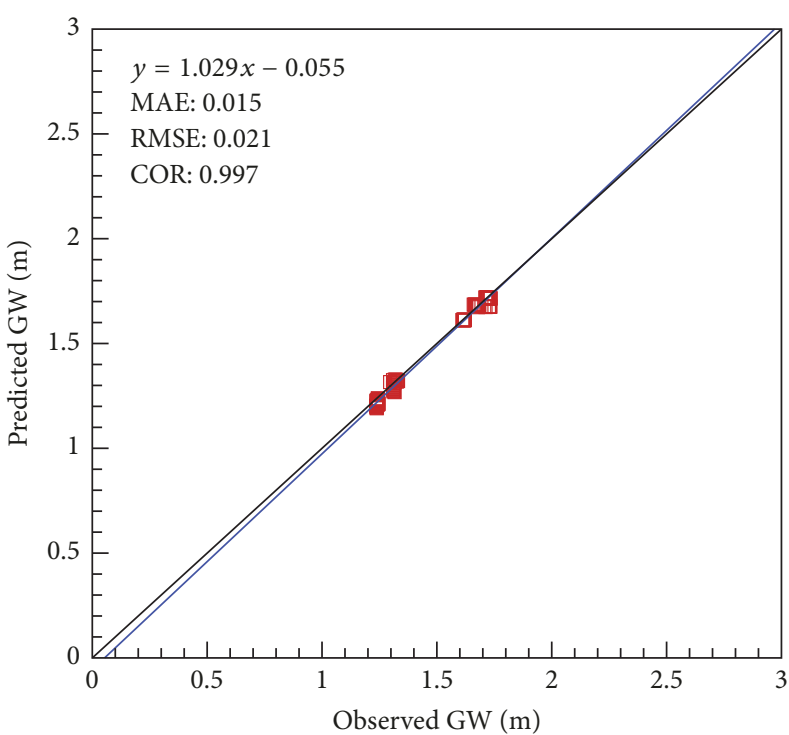

(a)

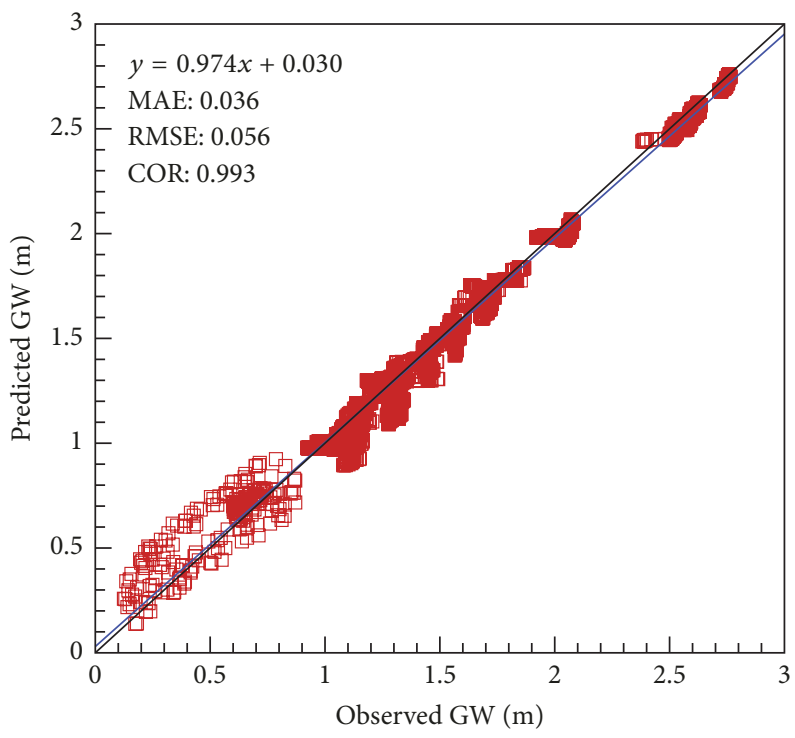

(c)

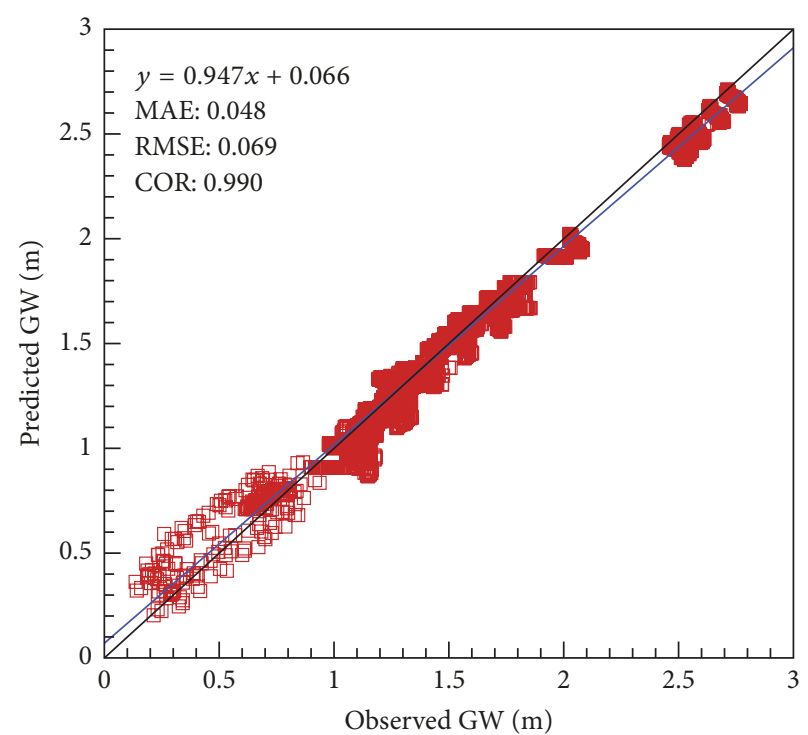

(b)

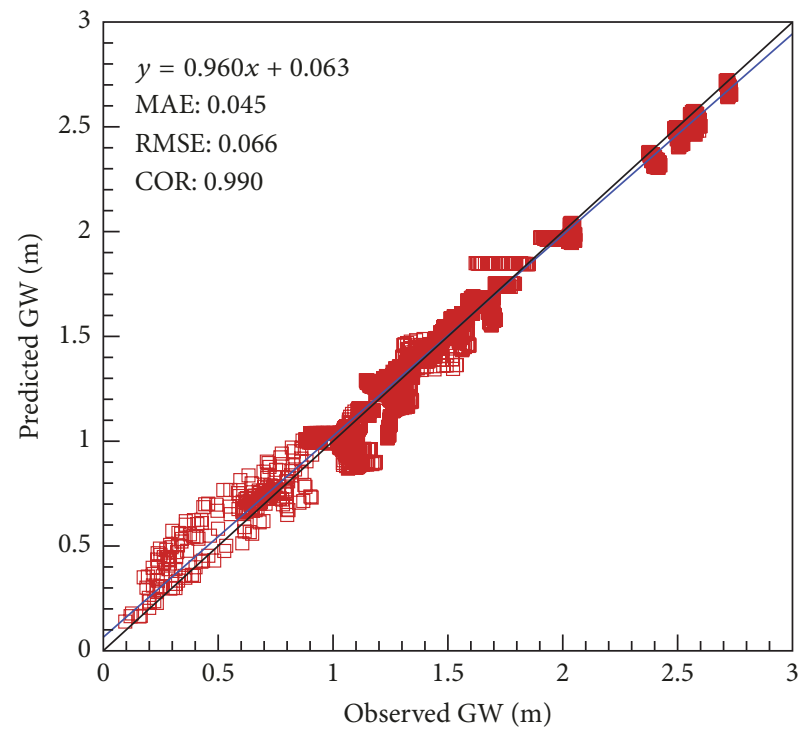

(d)

FIGURE 13: Scatter plots of the predicted groundwater levels of the optimal estimated heterogeneous $\alpha$ field and the observed groundwater levels of the historical records in the real aquifer. (a) Groundwater level results of the 5 observation wells at 24 hr; (b) groundwater level results of the 55 observation wells at $72 \mathrm{hr}(01 / 08 / 2014 \sim 01 / 10 / 2014)$; (c) groundwater level results of the 55 observation wells at 72 hr (01/11/2014 01/13/2014); and (d) groundwater level results of the 55 observation wells at $72 \mathrm{hr}(01 / 14 / 2014 \sim 01 / 16 / 2014)$.

correspond to the high $\alpha$ regions that are close to the perimetric boundary of the artificial island. These regions are affected the most by the tidal fluctuation. By comparing the optimal estimated heterogeneous $\alpha$ field and the uncertainty field of the estimated $\alpha$, it can be observed that the estimated results near the high $\alpha$ regions are more reliable. Moreover, by comparing the predicted groundwater levels of the optimal estimated heterogeneous $\alpha$ field and the observed groundwater levels of the historical records of the real aquifer, we found that the correlation was higher than 0.99 . This proves that the HT can be successfully used for obtaining the optimal estimated heterogeneous $\alpha$ field in the artificial island.

\section{Disclosure}

An earlier version of this work was presented as an abstract at American Geophysical Union, Fall Meeting 2015. The corresponding author can provide the data of this study upon request.

\section{Conflicts of Interest}

The authors declare that they have no conflicts of interest. 


\section{Acknowledgments}

Jet-Chau Wen would like to acknowledge the research support from NSC 101-2221-E-224-050, NSC 102-2221-E-224050, MOST 103-2221-E-224-054, MOST 104-2221-E-224-039, MOST 105-2625-M-224-002, and 106-2119-M-224-001 by the Minister of Science and Technology, Taiwan. Tian-Chyi Jim Yeh also acknowledges the Outstanding Overseas Professorship award through Jilin University by the Department of Education, China, as well as the Global Expert award through Tianjin Normal University from the Thousand Talents Plan of Tianjin City, support from the U.S. Environmental Security Technology Certification Program (ESTCP) Grant ER201212, and the NSF EAR Grant 1014594. The authors would like to thank the Formosa Petrochemical Corporation for providing the original groundwater data of 45 observation wells and also to thank Dr. Chia-Yii Yu's efforts in the structural modifications and manuscript polishing.

\section{Supplementary Materials}

Additional supplementary material may be found in the online version of this article: Text S1: long-term groundwater levels of the 55 observation wells. The long-term groundwater levels of the 55 observation wells are shown in Figure S1 (a bc). The long-term groundwater levels of each observation well present a significant impact due to the precipitation recharge in May 2014. Moreover, the long-term groundwater levels of the observation wells ob03, ob09, ob24, ob39, and ob43 are affected the most by tidal fluctuation. Figure S1 (a bc): long-term rainfall, tidal, and groundwater levels of each observation well during the period 11/07/2013 05/27/2014. (Supplementary Materials)

\section{References}

[1] M. A. Grant and M. L. Sorey, "The compressibility and hydraulic diffusivity of a water-steam flow," Water Resources Research, vol. 15, no. 3, pp. 684-686, 1979.

[2] C. Knudby and J. Carrera, "On the use of apparent hydraulic diffusivity as an indicator of connectivity," Journal of Hydrology, vol. 329, no. 3-4, pp. 377-389, 2006.

[3] F. A. L. Pacheco and C. H. Van der Weijden, "Role of hydraulic diffusivity in the decrease of weathering rates over time," Journal of Hydrology, vol. 512, pp. 87-106, 2014.

[4] P. M. Meier, J. Carrera, and X. Sánchez-Vila, "An evaluation of Jacob's method for the interpretation of pumping tests in heterogeneous formations," Water Resources Research, vol. 34, no. 5, pp. 1011-1025, 1998.

[5] C.-M. Wu, T.-C. J. Yeh, J. Zhu et al., "Traditional analysis of aquifer tests: Comparing apples to oranges?” Water Resources Research, vol. 41, no. 9, Article ID W09402, pp. 1-12, 2005.

[6] S.-Y. Huang, J.-C. Wen, T.-C. J. Yeh et al., "Robustness of joint interpretation of sequential pumping tests: Numerical and field experiments," Water Resources Research, vol. 47, no. 10, Article ID W10530, 2011.

[7] T. T. Eaton, "On the importance of geological heterogeneity for flow simulation," Sedimentary Geology, vol. 184, no. 3-4, pp. 187201, 2006.
[8] A. Russian, M. Dentz, T. Le Borgne, J. Carrera, and J. JimenezMartinez, "Temporal scaling of groundwater discharge in dual and multicontinuum catchment models," Water Resources Research, vol. 49, no. 12, pp. 8552-8564, 2013.

[9] D. Pedretti, A. Russian, X. Sanchez-Vila, and M. Dentz, "Scale dependence of the hydraulic properties of a fractured aquifer estimated using transfer functions," Water Resources Research, vol. 52, no. 7, pp. 5008-5024, 2016.

[10] M. Cardiff, W. Barrash, P. K. Kitanidis et al., "A potential-based inversion of unconfined steady-state hydraulic tomography," Groundwater, vol. 47, no. 2, pp. 259-270, 2009.

[11] W. A. Illman, X. Liu, S. Takeuchi, T.-C. J. Yeh, K. Ando, and H. Saegusa, "Hydraulic tomography in fractured granite: Mizunami Underground Research site, Japan," Water Resources Research, vol. 45, no. 1, Article ID W01406, 2009.

[12] S. J. Berg and W. A. Illman, "Comparison of Hydraulic Tomography with Traditional Methods at a Highly Heterogeneous Site," Groundwater, vol. 53, no. 1, pp. 71-89, 2015.

[13] J. Hodgkinson, M. E. Cox, S. McLoughlin, and G. J. Huftile, "Lithological heterogeneity in a back-barrier sand island: Implications for modelling hydrogeological frameworks," Sedimentary Geology, vol. 203, no. 1-2, pp. 64-86, 2008.

[14] F. Ghassemi, K. Alam, and K. W. F. Howard, "Fresh-water lenses and practical limitations of their three-dimensional simulation," Hydrogeology Journal, vol. 8, no. 5, pp. 521-537, 2000.

[15] C. Ruppel, G. Schultz, and S. Kruse, "Anomalous fresh water lens morphology on a strip barrier island," Groundwater, vol. 38 , no. 6, pp. 872-881, 2000.

[16] R. W. Ritzi Jr., J. M. Bukowski, C. K. Carney, and M. R. Boardman, "Explaining the thinness of the fresh water lens in the pleistocene carbonate aquifer on Andros Island, Bahamas," Groundwater, vol. 39, no. 5, pp. 713-720, 2001.

[17] H. Guo and J. J. Jiao, "Impact of coastal land reclamation on ground water level and the sea water interface," Groundwater, vol. 45, no. 3, pp. 362-367, 2007.

[18] L. Hu, J. J. Jiu, and H. Guo, "Analytical studies on transient groundwater flow induced by land reclamation," Water Resources Research, vol. 44, no. 11, Article ID W11427, 2008.

[19] H. Li, J. J. Jiao, and Z. Tang, "Semi-numerical simulation of groundwater flow induced by periodic forcing with a case-study at an island aquifer," Journal of Hydrology, vol. 327, no. 3-4, pp. 438-446, 2006.

[20] A. D. Erskine, "The Effect of Tidal Fluctuation on a Coastal Aquifer in the UK," Groundwater, vol. 29, no. 4, pp. 556-562, 1991.

[21] Y. Fakir and M. Razack, "Hydrodynamic characterization of a Sahelian coastal aquifer using the ocean tide effect (Dridrate Aquifer, Morocco)," Hydrological Sciences Journal, vol. 48, no. 3, pp. 441-454, 2003.

[22] M. K. Jha, D. Namgial, Y. Kamii, and S. Peiffer, "Hydraulic parameters of coastal aquifer systems by direct methods and an extended tide-aquifer interaction technique," Water Resources Management, vol. 22, no. 12, pp. 1899-1923, 2008.

[23] X. Zhou, "Determination of aquifer parameters based on measurements of tidal effects on a coastal aquifer near Beihai, China," Hydrological Processes, vol. 22, no. 16, pp. 3176-3180, 2008.

[24] L. W. Gelhar, "Stochastic analysis of phreatic aquifers," Water Resources Research, vol. 10, no. 3, pp. 539-545, 1974.

[25] D. C.-F. Shih and G.-F. Lin, "Application of spectral analysis to determine hydraulic diffusivity of a sandy aquifer (Pingtung 
County, Taiwan)," Hydrological Processes, vol. 18, no. 9, pp. 16551669, 2004.

[26] A.-Z. Hsia, R.-X. Zheng, and T.-S. Dong, "Investigation and verification of soil and groundwater pollution potential in Yunlin offshore industrial park," Report no. 100-033, Department of Environmental Protection, Yunlin, Taiwan, Report, 2012.

[27] L. K. Chien and M. C. Lin, "Evaluation of shear wave velocity for reclaimed soil-a case study of MAI-LIAW region nearshore area," Sion-Geotechnics, vol. 67, pp. 69-82, 1998.

[28] R. A. Freeze and J. A. Cherry, Groundwater, Prentice-Hall, Englewood Cliffs, New Jersey, NJ, USA, 1979.

[29] J. Bear, Hydraulics of Groundwater, New York, MacGraw-Hill, 1979.

[30] T.-C. J. Yeh, R. Srivastava, A. Guzman, and T. Harter, "A Numerical Model for Water Flow and Chemical Transport in Variably Saturated Porous Media," Groundwater, vol. 31, no. 4, pp. 634-644, 1993.

[31] J. S. Walker, "Fourier analysis and wavelet analysis," Notices, vol. 44, no. 6, pp. 658-670, 1997.

[32] L. Tremblay, M. Larocque, F. Anctil, and C. Rivard, "Teleconnections and interannual variability in Canadian groundwater levels," Journal of Hydrology, vol. 410, no. 3-4, pp. 178-188, 2011.

[33] M. Onderka, S. Banzhaf, T. Scheytt, and A. Krein, "Seepage velocities derived from thermal records using wavelet analysis," Journal of Hydrology, vol. 479, pp. 64-74, 2013.

[34] J.-B. Charlier, B. Ladouche, and J.-C. Maréchal, "Identifying the impact of climate and anthropic pressures on karst aquifers using wavelet analysis," Journal of Hydrology, vol. 523, pp. 610623, 2015.

[35] J. P. Sánchez-Úbeda, M. L. Calvache, C. Duque, and M. LópezChicano, "Filtering methods in tidal-affected groundwater head measurements: Application of harmonic analysis and continuous wavelet transform," Advances in Water Resources, vol. 97, pp. 52-72, 2016.

[36] Y.-L. Wang, T.-C. J. Yeh, J.-C. Wen et al., "Characterizing subsurface hydraulic heterogeneity of alluvial fan using riverstage fluctuations," Journal of Hydrology, vol. 547, pp. 650-663, 2017.

[37] C. Torrence and G. P. Compo, "A practical guide to wavelet analysis," Bulletin of the American Meteorological Society, vol. 79, no. 1, pp. 61-78, 1998.

[38] T.-C. J. Yeh, M. Jin, and S. Hanna, "An iterative stochastic inverse method: Conditional effective transmissivity and hydraulic head fields," Water Resources Research, vol. 32, no. 1, pp. 85-92, 1996.

[39] J. Zhang and T.-C. J. Yeh, "An iterative geostatistical inverse method for steady flow in the vadose zone," Water Resources Research, vol. 33, no. 1, pp. 63-71, 1997.

[40] J. Zhu and T.-C. J. Yeh, "Characterization of aquifer heterogeneity using transient hydraulic tomography," Water Resources Research, vol. 41, no. 7, pp. 1-10, 2005.

[41] X. Liu, W. A. Illman, A. J. Craig, J. Zhu, and T.-C. J. Yeh, "Laboratory sandbox validation of transient hydraulic tomography," Water Resources Research, vol. 43, no. 5, Article ID W05404, 2007.

[42] T.-C. J. Yeh, J. Xiang, R. M. Suribhatla, K.-C. Hsu, C.-H. Lee, and J.-C. Wen, "River stage tomography: A new approach for characterizing groundwater basins," Water Resources Research, vol. 45, no. 5, Article ID W05409, 2009.

[43] M. J. L. Robin, A. L. Gutjahr, E. A. Sudicky, and J. L. Wilson, "Cross-correlated random field generation with the direct Fourier Transform Method," Water Resources Research, vol. 29, no. 7, pp. 2385-2397, 1993. 

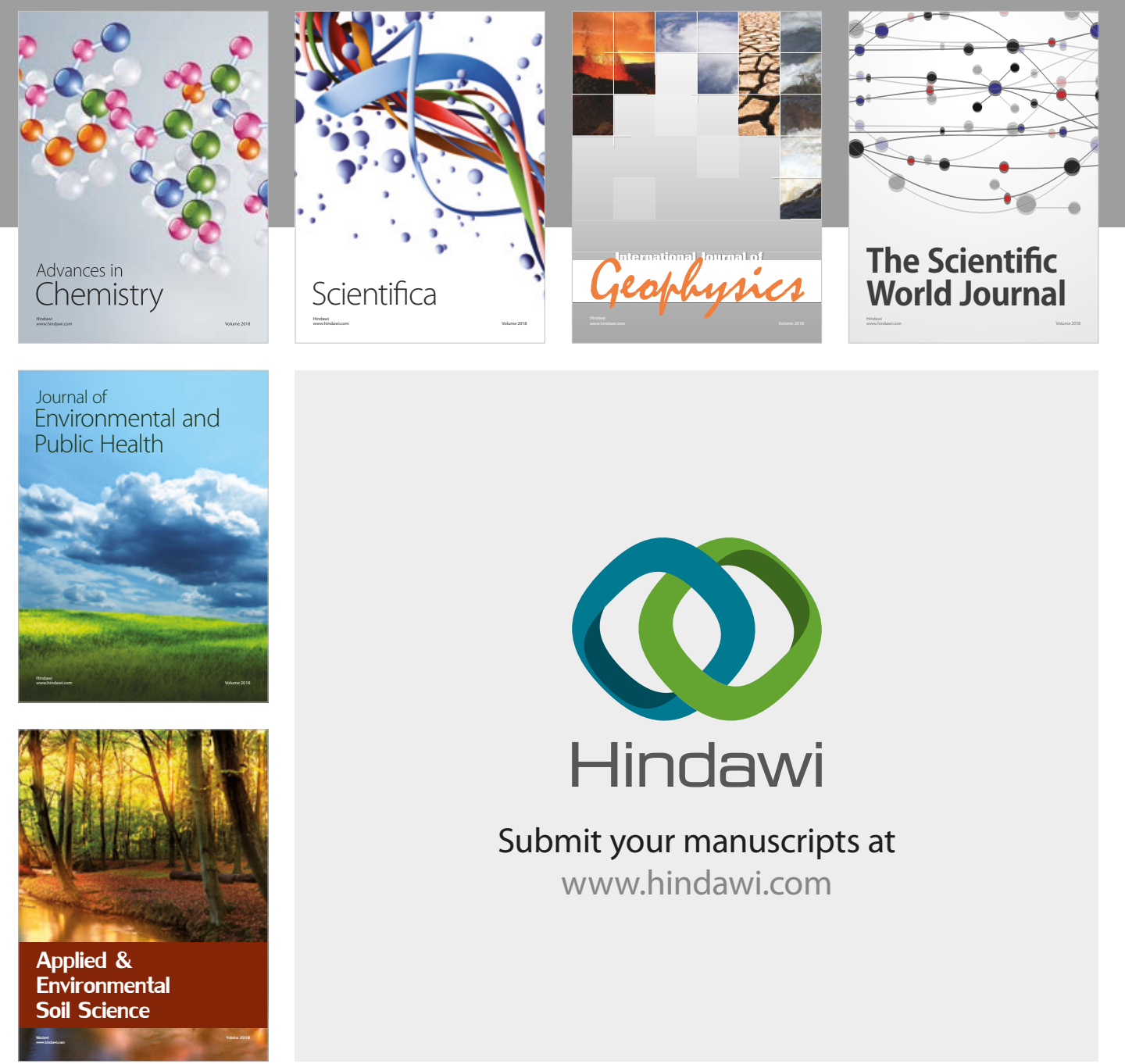

The Scientific

\section{World Journal}
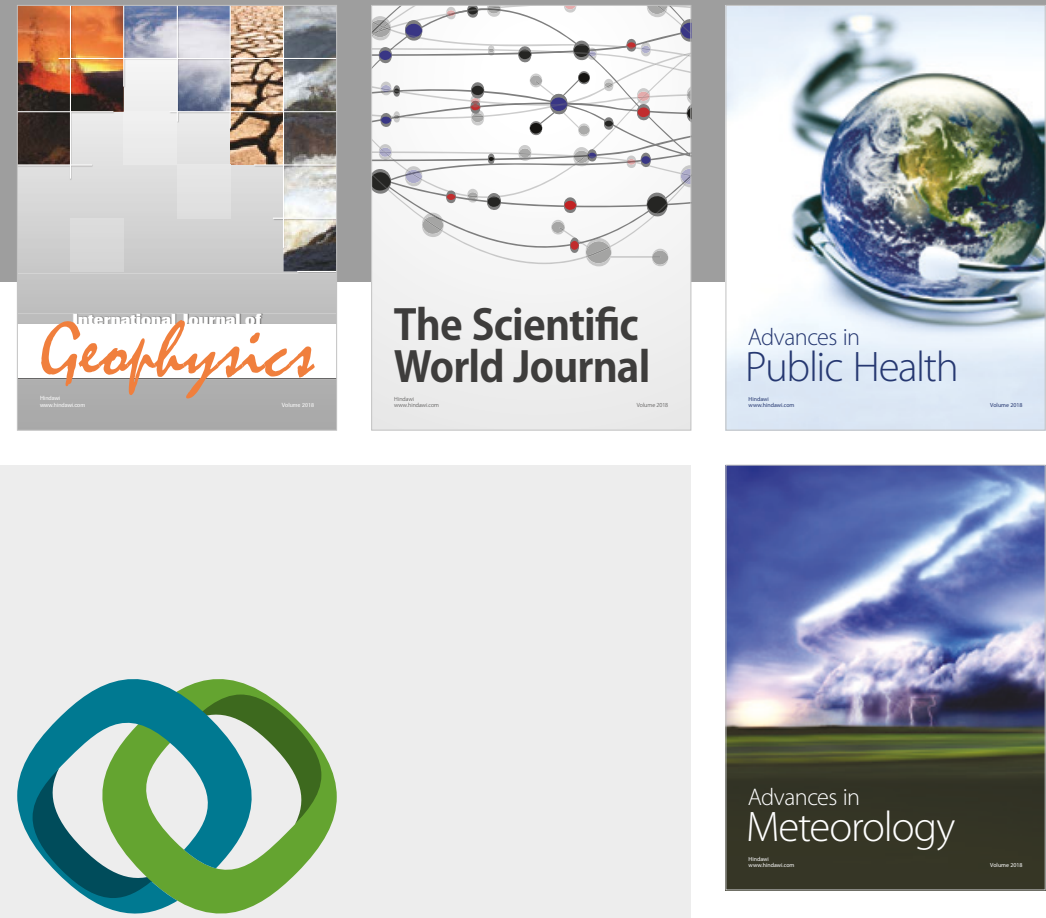

Advan

Public Health

\section{Hindawi}

Submit your manuscripts at

www.hindawi.com
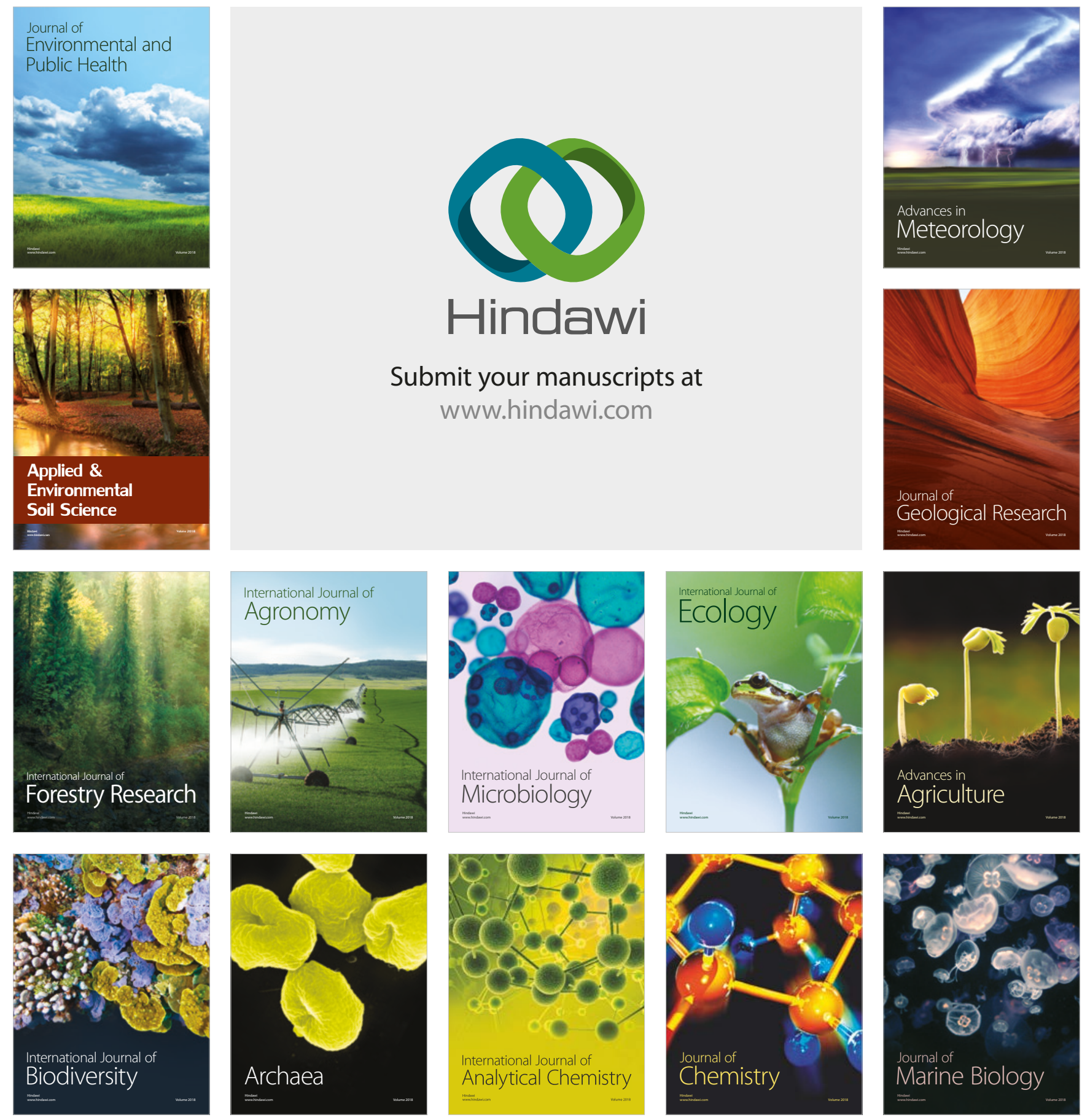